\title{
Supplementary Information for: Ambient gas-particle partitioning of tracers for biogenic oxidation
}

Gabriel Isaacman-VanWertz ${ }^{\dagger,}$, Lindsay D. Yee ${ }^{\dagger}$, Nathan M. Kreisberg ${ }^{\S}$, Rebecca Wernis", Joshua A. Moss ${ }^{\dagger,}$, Susanne V. Hering ${ }^{\S}$, Suzane S. de Sá, Scot T. Martin ${ }^{\%, J}$, M. Lizabeth Alexander ${ }^{\perp}$, Brett B. Palm ${ }^{\#}$, Weiwei Hü, Pedro Campuzano-Jost”, Douglas A. Day ${ }^{\#}$, Jose L. Jimenez $^{\#}$, Matthieu Riva ${ }^{\Uparrow}$, Jason D. Surratt", Juarez Viegas ${ }^{\mathbf{\Lambda}}$, Antonio Manzi ${ }^{\mathbf{\Lambda}}$, Eric Edgerton ${ }^{\square}$,

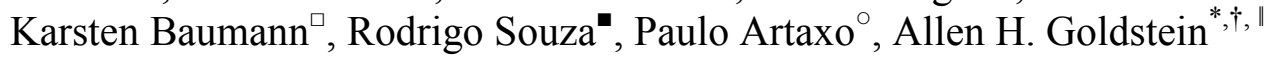

$\dagger$ Dept. of Environmental Science, Policy, and Management, University of California, Berkeley, CA, USA, 94720

12 §Aerosol Dynamics Inc., Berkeley, CA, USA, 94710

$13 \|$ Dept. of Civil and Environmental Engineering, University of California, Berkeley, CA, USA, $14 \quad 94720$

\%School of Engineering and Applied Sciences, Harvard University, Cambridge, MA, USA, 01451

17 Dept. of Earth and Planetary Sciences, Harvard University, Cambridge, MA, USA, 01451

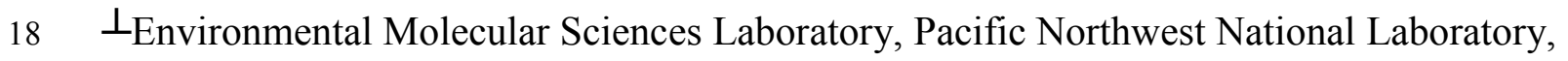

19 Richland, WA, USA, 99352

20 \#Dept. of Chemistry \& Biochemistry and Cooperative Institute for Research in Environmental 21 Sciences (CIRES), University of Colorado, Boulder, CO, USA, 80309

qDept. of Environmental Sciences and Engineering, University of North Carolina, Chapel Hill, 23 NC, USA, 27599

$24 \Delta$ Instituto Nacional de Pesquisas da Amazonia, Manaus, AM, Brazil, 69060-001

$25 \square$ Atmospheric Research \& Analysis, Inc., Cary, NC, USA, 27513

-Universidade do Estado do Amazonas, Manaus, AM, Brazil, 69735-000

27 oUniversidade de São Paulo, São Paulo, SP, Brazil, 05508-020 
29 Supplementary Information includes 43 pages:

30 S1. Materials and Methods

31 S1.1. Measurement locations, $p . S 3$

$32 \quad \mathrm{~S} 1.2$. Instrumentation, $p . S 3$

33 S1.3. Models, p. S9

34 S2. Supporting results

35 S2.1. Particle composition and water content, $p$. S13

$36 \quad \mathrm{~S} 2.2$. Observed variability in partitioning, $p$. S14

$37 \quad \mathrm{~S} 2.3$. Average partitioning values, $p$. S16

$38 \quad$ S3. Supporting references, $p$. $S 17$

39 S4. Figures S1-S19, p. S21

$40 \quad \mathrm{~S} 5$. Tables $\mathrm{S} 1-\mathrm{S} 7$, p. $S 38$

41 


\section{S1. Materials and Methods}

\section{S1.1. Detailed site descriptions}

Locations of both measurements sites are shown in, Fig. S1, colored by dominant land cover: forests in green, cropland in yellow, and urban in red.

\section{S1.1.1. SOAS: Southeastern U.S.}

Emissions of VOCs at the SOAS CTR ground site in Centreville, AL are expected to be predominantly biogenic with relatively little local influence. Anthropogenic emissions from Tuscaloosa, AL ( $\sim 40 \mathrm{~km} \mathrm{NW)}$ or Birmingham, AL ( $\sim 80 \mathrm{~km} \mathrm{NE})$ are expected to have some influence on regional oxidation chemistry, though winds were more often southerly during this period, as seen in Fig. S1b. Samples were collected at $\sim 5 \mathrm{~m}$ a.g.l. in a clearing on a small hill (elevation gain of 10-20 m from the tree line) tens of meters from the tree line in most directions: $40 \mathrm{~m}$ from the tree line to the east and west and $130 \mathrm{~m}$ south of the CTR measurement tower and tree line. The tree line is $250 \mathrm{~m}$ from the site toward the southwest, which is also the location of the nearest road.

\section{S1.1.2. GoAmazon2014/5: Amazonia, Brazil}

Samples were collected at $\sim 5 \mathrm{~m}$ a.g.l. at the eastern edge of the measurement site; the tree line began approximately $500 \mathrm{~m}$ east (upwind) of the sample inlet. T3 was bounded on the west edge by a little used gravel road ( $50 \mathrm{~m}$ from sample inlet) and was surrounded by mostly unused pastureland. A diesel generator at the west edge of the measurement site provided power during municipal power outages so these periods have been removed from comparisons with bulk aerosol measurements (i.e. AMS organics, see description below). Approximately half of the time, the site of the GoAmazon 2014/5 measurements ("T3") was strongly influenced by the emissions of Manaus, which has been shown previously to have a strong effect on the chemical processing of emissions. ${ }^{1,2}$ However, no clear difference in the fraction of mass comprised of these tracers is observed in periods with and without apparent influence from nearby urban outflow, so these time periods have not been separated for this work.

\section{S1.2. Instrumentation}

\section{S1.2.1. SV-TAG: Semi-Volatile Thermal desorption Aerosol Gas chromatograph}

Organic tracer compounds are measured in the particle and gas phases using a SemiVolatile Thermal desorption Aerosol Gas chromatograph (SV-TAG) employing two parallel sampling cells and in situ derivatization. The instrument used in this work is described in detail elsewhere, ${ }^{3}$ so is only discussed in brief here. Air is sampled through a $\mathrm{PM}_{1}$ cyclone at 10 liters per minute (Lpm) into each custom Filter Collection and Thermal Desorption cell (F-CTD), consisting of a high surface-area metal fiber filter in a stainless steel housing to allow controlled heating and forced air cooling. In addition to particles, the F-CTD quantitatively collects and retains gas-phase compounds with a volatility lower than that of tetradecane, allowing direct measurement of gas-particle partitioning for low volatility gases using a denuder difference technique. ${ }^{4}$ Simultaneous collection of a "particle" sample and a "total" gas-plus-particle sample is achieved using a multi-channel carbon monolith denuder (500 channels, $30 \mathrm{~mm}$ OD x 40.6 $\mathrm{cm}$; MAST Carbon) to remove all gases upstream of one collection cell. Particle fraction, $F_{P}$, is 
calculated from the direct comparison between the two samples, yielding an uncertainty of approximately $20 \%$ of measured $F_{P}$; for example, a sample with observed $F_{P}=0.40$, is expected to have a true value in the range of $0.30-0.50$. Note that as a comparison between two independent measurements and due to instrument uncertainty, values of $1.0<F_{P}<1.2$ are not unexpected and can be interpreted as being within error of $F_{P}=1$. Gas-phase semi-volatile compounds are expected to easily condense on surfaces, so residence time in the inlet is minimized by sub-sampling $20 \mathrm{lpm}$ from the center stream of a $200 \mathrm{lpm}, 6$ " stainless steel duct (cleaned with isopropanol and heat treatment) with a height of approximately $5 \mathrm{~m}$. Sample flow is brought from this duct to the collection cells through less than $1 \mathrm{~m}$ of 3/8" O.D. stainless steel tubing. Potential artifacts from penetration of gas-phase compounds through the denuder are corrected by occasionally placing a filter in-line with the denuder and subtracting any remaining measured mass as a fraction of the simultaneously collected gas-plus-particle mass.

Samples are thermally desorbed from the cells into a helium stream $80 \%$ saturated with MSTFA (N-Methyl-N-(trimethylsilyl) trifluoroacetamide), which converts all hydroxyl groups into silyl esters and ethers. To minimize exposure of analytes to temperatures higher than necessary for desorption, the temperature of the sampling cell ramps over 8 minutes from $30{ }^{\circ} \mathrm{C}$ to $310{ }^{\circ} \mathrm{C}\left(35^{\circ} \mathrm{C} / \mathrm{min}\right)$, where it is held for 3 minutes. It must be noted that the reactions of silylating agents with some atmospherically relevant functional groups, such as hydroperoxides, organosulfates, and organonitrates, have not been extensively studied here or elsewhere, and may yield products indistinguishable from hydroxyl analogues. This potential measurement artifact is discussed explicitly in the interpretation of the data and the comparison between SV-TAG measurements and filter samples are favorable (Sect. S1.2.5). Following thermal desorption, sample is re-condensed onto an intermediate focusing trap $(\sim 100 \mathrm{~cm}$ of $0.53 \mathrm{~mm}$ ID x $5 \mu \mathrm{m}$ MXT-5 chromatography column; Restek) at approximately $35^{\circ} \mathrm{C}$, which is then backflushed and heated over 3 minutes up to $310^{\circ} \mathrm{C}$, where it is held for 2 minutes, transferring analytes to the GC column. This two-step purge-and-trap method allows high desorption flows (up to $150 \mathrm{sccm}$ ) and removes compounds too volatile to be trapped, such as excess derivatizing agent and byproducts, but prevents quantitative analysis of compounds with retention times earlier than that of approximately tridecane, nonanoic acid, or butanedioic acid. Once transferred to the GC column (Rtx-5Sil MS, 20m x $0.18 \mathrm{~mm} \times 0.18 \mu \mathrm{m}$; Restek), the sample is analyzed through a commercially available GC/MS (7890A/5975C; Agilent Technologies). The temperature program of the $\mathrm{GC}$ analysis ramped from $50{ }^{\circ} \mathrm{C}$ to $330{ }^{\circ} \mathrm{C}$ over $11.9\left(23.6{ }^{\circ} \mathrm{C} / \mathrm{min}\right)$ minutes with helium flow at $1 \mathrm{sccm}$ and held at that temperature for 2.2 minutes while flow is ramped to 3 sccm to elute any compounds with low vapor pressure. All chromatographic data were reduced and analyzed using custom analysis code written in Igor Pro 6.3 (WaveMetrics), which forms the basis of the publicly available software TAG ExploreR and iNtegration. ${ }^{5}$

Run-to-run variability in instrument parameters is accounted for using isotopically labeled internal standards with atmospherically relevant functionality and volatility. Highly oxygenated compounds suffer a greater reduction in signal in denuded samples, so selection of an internal standard with a degree of oxygenation significantly different than that of the analyte can result in a bias in $F_{P}$. To explore this potential bias, the average $F_{P}$ of all compounds observed during IOP1 is shown in Fig. S2 using both shown pentaerythritol-2- ${ }^{13} \mathrm{C}$ (a highly oxygenated internal standard) and pentadecanol- $\mathrm{d}_{31}$ (a slightly oxygenated internal standard) to correct for run-to-run variability. The degree of potential bias is found to be less than $4 \%$ and within error of nearly all compounds, so pentaerythritol- $2-{ }^{13} \mathrm{C}$ is used for all compounds due to the high degree of oxygenation expected for most BVOC oxidation products 
Authentic standards are used in this work for quantification of 2-methyltetrols, the synthesis of which is described by Budisulistiorini et al. ${ }^{6}$ Both 2-methylerthritol and 2methylthreitol (m/z 219) are quantified in the field using the response of erythritol, then corrected based the relative response of 2-methyltetrols and erthythritol on a different thermal desorption GC. For these compounds, uncertainty in mass is approximately $15 \%$, calculated using the methods described by Isaacman et al. ${ }^{3}$. $\mathrm{C}_{5}$ alkene triols are quantified using the calibration factor of 2-methyltetrols assuming identical total ion response; lack of an authentic standard results in unconstrained uncertainty in mass accuracy of $30-50 \% .{ }^{7} F_{P}$ is measured as a direct comparison of analyte signal at each point, with approximately $20 \%$ uncertainty. Timeintegrated (i.e. diurnal or campaign-long) median or average particle fractions are measured with much more certainty as they are a function of sample size. In this work, uncertainties on diurnal averages of $F_{P}$ of identified compounds are $\sim 5 \%$, while average particle fraction across the entire campaign of any compound can be measured with $<5 \%$ uncertainty. $F_{P}$ is calculated from measured concentrations in two independent sampling cells, so measurements of $F_{P}>1$ are possible due to measurement uncertainties. ${ }^{3}$

\section{S1.2.2. AMS: Aerodyne Aerosol Mass Spectrometer}

Non-refractory submicron particle-phase mass at both field sites was measured by an Aerodyne High Resolution Time-of-Flight Aerosol Mass Spectrometer (HR-ToF-AMS, hereafter called AMS) to quantify OA, sulfate, nitrate, ammonium, and chloride ${ }^{8}$ and oxygen-to-carbon ratios $(\mathrm{O}: \mathrm{C})$ of OA. ${ }^{9,10}$ An aerodynamic lens ${ }^{11}$ focuses submicron particles into a beam for volatilization by a $600{ }^{\circ} \mathrm{C}$ vaporizer and analysis by electron impact and time-of-flight mass spectrometry. Data analysis was performed using standard AMS software (SQUIRREL1.52M, PIKA1.15D) available online. ${ }^{12}$

For SOAS, the AMS sensitivity and ammonium relative ionization efficiency (RIE) was calibrated every few days using dried $400 \mathrm{~nm}$ ammonium nitrate particles. The sulfate RIE was calibrated multiple times during the campaign, the variation of which was within $3 \%$. Collection efficiency $(\mathrm{CE})$ was calculated using the composition-dependent formulation of Middlebrook et al. ${ }^{13}$, and was 0.5-0.6. Ambient air was sampled at $10 \mathrm{lpm}$ via a PM2.5 cyclone (URG corporation) which immediately passed through a poly-tube nafion drier (Perma Pure LCC, PD50T-12-MSS), then through a 0.375 " OD and 0.311 " $\mathrm{mm}$ ID) $2.5 \mathrm{~m}$ long Stainless Steel tube into the temperature-controlled trailer. $\mathrm{RH}$ in the $10 \mathrm{lpm}$ flow once in the trailer was always $<60 \%$ (and typically $<50 \%$ ). Within the trailer, $0.7 \mathrm{lpm}$ was split from the main flow for sampling by the AMS and SMPS (0.25" OD, 0.194” ID), passed through a single-membrane nafion drier (Perma Pure LCC, MD-110-24S-4) to reach RH $<30 \%$ and $0.1 \mathrm{lpm}$ was sampled by the AMS. We controlled the flow to be laminar flow for the whole time and the total residence time is around 16s. The AMS alternated between sampling unprocessed ambient air and air processed by oxidation flow reactors or a thermal denuder, with unprocessed ambient air (used for this analysis) sampled for 4 minutes every other 4 minutes.

Measurements at GoAmazon2014/5 were collected using the same methodology, with the exception of: 1) the CE was determined to be 1 for IOP 1 and 0.5 (composition-dependent) for IOP2 according to volume comparison to two co-located Scanning Mobility Particle Sizers, 2) $\mathrm{RH}$ after the first nafion drier (poly-tube) and inside the trailer was always below $80 \%$, and 3 ) $\mathrm{RH}$ after the second nafion drier (single-tube) was always below $40 \%$. 


\section{S1.2.3. Meteorological data}

At the SOAS ground site, ambient air temperature $(\mathrm{T})$ and relative humidity $(\mathrm{RH})$ were measured by a fan-aspirated $(\sim 3 \mathrm{~m} / \mathrm{s}$ ) and solar radiation shielded sensor (MET4A from Paroscientific, Inc., Redmond, WA) located $9 \mathrm{~m}$ agl. The sensor combined a 3-wire Pt100 with a capacitive filament in the HygroClip2 probe (Rotronic Instrument Corp., Huntington, NY). Sensor accuracy is specified at better than $\pm 0.1{ }^{\circ} \mathrm{C}$ and $\pm 0.8 \% \mathrm{RH}$ over the encountered range of ambient $\mathrm{T}$ and $\mathrm{RH}$, respectively.

Ammonia $\left(\mathrm{NH}_{3}\right)$ was measured at the SOAS ground site by denuder difference technique, described in detail by Saylor et al. ${ }^{14}$ This technique employs a dual-channel $\mathrm{NO}_{-} \mathrm{O}_{3}$ chemiluminescence detector (CLD). Ambient air on both channels flows through sodium carbonate (Na2CO3)-coated annular denuders (URG, Inc., Chapel Hill, NC) at a flow rate of $1.25 \mathrm{lpm} . \mathrm{NH}_{3}$ quantitatively passes through the denuders whereas $\mathrm{HNO} 3$ and other reactive $\mathrm{NO}_{\mathrm{y}}$ components are removed. Channel 2 flow goes directly into a $600^{\circ} \mathrm{C}$ platinum $(\mathrm{Pt})$ mesh converter followed by a $350^{\circ} \mathrm{C}$ molybdenum (Mo) converter. The Pt converter oxidizes $\mathrm{NH}_{3}$ and particulate $\mathrm{NH}_{4}{ }^{+}$to $\mathrm{NO}$ and $\mathrm{NO}_{2}$. The Mo backup converter reduces all $\mathrm{NO}_{\mathrm{y}}$ components to NO. Channel 1 flow is directed through a citric acid-coated annular denuder to remove $\mathrm{NH}_{3}$ prior to the sequential oxidizing $(\mathrm{Pt})$ and reducing $(\mathrm{Mo})$ conversion steps. The difference between Channel 2 and Channel 1 is therefore operationally defined as $\mathrm{NH}_{3}$. Other reduced nitrogen gases that are removed by a citric acid denuder may be included in this operational definition, thus causing a potential positive bias. Annular denuder inlets for each channel are exposed directly to the atmosphere and converters are attached to denuder outlets with short $(5 \mathrm{~cm})$ lengths of $1 / 4$ " o.d. PFA Teflon tubing to minimize the potential for adsorption of $\mathrm{NH}_{3}$ to interior instrument surfaces. Residence time upstream of the converters is kept to $<2 \mathrm{~s}$ in order to minimize line losses and decomposition of $\mathrm{NH}_{4} \mathrm{NO}_{3}$. Inlet denuders are replaced once per month. Measurements are made atop the equipment shelter at a height of approximately $5 \mathrm{~m}$ agl. The CLD is calibrated with NO every other day and zeroed with dry zero air once a day. One-minute averages are acquired from the CLD and used to calculate and report 5-min average, standard deviation, minimum, maximum and median statistics. The 5-min data can then be used to generate hourly averages and associated statistics. Measurement uncertainty and detection limit of the $5-\mathrm{min} \mathrm{NH}_{3}$ data were determined to be $\pm 15.1 \%$ and $0.08 \mathrm{ppbv}$, respectively.

Meteorological data for GoAmazon2014/5 was collected by the Mobile Aerosol Observing System and at the T3 site near Manacapuru, Brazil as part of the Atmospheric Radiation Measurement (ARM) Climate Research Facility.

\section{S1.2.4. Filter collection}

Filters were collected at the SOAS site to be used for offline analysis of identified and known tracers of biogenic oxidation products. Analysis of these filters is used in this work to provide the first comparison between SV-TAG field data to traditional measurement techniques for these tracers. Samples were collected on quartz fiber filters at $1000 \mathrm{Lpm}$, for, in most cases, 2 $\times 11$ hours per day (08:00 AM to 07:00 PM and 08:00 PM to 07:00 AM). During several short periods, four filters were collected per day to yield higher time resolution. Filters and aluminum foil were pre-cleaned by baking them in a furnace using the following protocol: (1) ramp up from room temperature to a set point of $550{ }^{\circ} \mathrm{C}$ over a 3.5 hour timeframe; (2) Bake for another 12 hours at $550^{\circ} \mathrm{C}$; and (3) end and cool down back to room temperature for 18 hours. After 
sample collection, all filters were stored in aluminum foil inside a clean and sealed anti-static bag, which was stored at $-20{ }^{\circ} \mathrm{C}$ until analysis. For chemical analysis, filters $(37 \mathrm{~mm}$ punch) were extracted with $20 \mathrm{~mL}$ of high-purity methanol (LC-MS Chromasolv-grade ${ }^{\circledR}$, Sigma Aldrich) by sonication for $45 \mathrm{~min}$. Extracts were then filtered through $0.2-\mu \mathrm{m}$ PTFE syringe filters (Pall Life Science, Acrodisc) to remove insoluble particles or quartz filter fibers and then blown dry under a gentle $\mathrm{N}_{2}$ (g) stream at ambient temperature. Dried filter extracts were trimethylsilylated by addition of $100 \mu \mathrm{L}$ BSTFA + trimethylchlorosilane (99:1 (v/v), Supelco) and $50 \mu \mathrm{L}$ pyridine (Sigma-Aldrich, 98\%, anhydrous) at $70{ }^{\circ} \mathrm{C}$ for 60 minutes. Analysis were then performed by GC/EI-MS at $70 \mathrm{eV}$ (Hewlett 5890 Packard Series II Gas Chromatograph interfaced to a HP 5971A Series Mass Selective Detector, Econo-CapTM-ECTM-5 column, $30 \mathrm{~m} \times 0.25 \mathrm{~mm} \times$ $0.25 \mu \mathrm{m})$.

\section{S1.2.5. Experimental validation of $F_{P}$ measurements}

Many of the biogenic oxidation products discussed in this work have been measured regularly over the past decade and used to understand sources and formation processes of organic aerosol. Prior to the implementation of in-field derivatization on SV-TAG, measurements of these compounds has been limited to filter collection, followed by, in most cases, solvent extraction, and laboratory analysis. Due to the sample sizes and labor necessary for these techniques, time resolution for biogenic oxidation products has therefore been historically limited to 12 or 24-hour samples, with occasional sample collection down to 3-hour time resolution. The measurements presented here are therefore a dramatic advance in time resolution, and comparison between SV-TAG measurements and traditional filter-based techniques provides validation of the concentrations reported in this work. Only points with $F_{P}>0.8$ (that is, within approximate error of $F_{P}=1$ ) are used in the comparison. This prevents possible measurement artifacts on the filter caused by gas-phase adsorption, which is known to be an important concern in the case of quartz fiber filters. ${ }^{15}$ Both 2 -methyltetrols generally agree with measurements from the filters (Fig. S3a,b), with most points near unity. There are a few periods that have a clear positive bias in SV-TAG measurements, up to approximately 2:1. On average SV-TAG measurements are $50 \%$ higher than filter-based concentrations, driven primarily by a small number of high data points. During these periods, it is possible that some thermal decomposition of low-volatility products occurs in SV-TAG that is absent from filter-based measurements. But this explanation would mean that only up to $33 \%$ of the particle-phase concentration measured is due to decomposition of low-volatility products that occurs in SV-TAG and not in traditional filter extraction techniques, and even then only a small fraction of the data has a discrepancy this large, with most points within instrumental errors of unity. The average inferred decomposition of low-volatility products that is unique to SV-TAG is well below the average difference between predicted and observed $F_{P}$, and this process cannot explain periods during which up to $95 \%$ of mass must be low-volatility products to explain the observations. This does not preclude decomposition as a measurement artifact in the observed $F_{P}$, but rather implies that filter-based measurements may also be subject to some decomposition. Comparing the two measurement techniques for levoglucosan (Fig. S3c), a commonly measured tracer for biomass burning, shows some scatter but does not exhibit the same biases and clusters around unity. This suggests that SV-TAG and filter extraction are in general agreement, even for oxygenated compounds, but each are subject to a different set of measurement artifacts that makes direct comparison difficult for labile species. 
Thermal decomposition of labile particle-phase constituents may lead to bias in the particle-phase concentration of some BVOC oxidation products. Of particular concern is decomposition of oligomers and derivatization of organosulfates and/or organonitrates. To test for this source of uncertainty, authentic organosulfate analogues were synthesized that could be expected to be derivatized into apparent 2 -methyltetrols. However, only negligible $(<5 \%)$ conversion was observed, suggesting that derivatization of organosulfates is unlikely to substantially contribute to excess particle-phase phase mass of the observed analogue. Conversion of organonitrates is not yet well constrained; however, nitrate groups and hydroxyl groups exhibit a similar impact on vapor pressure, ${ }^{16}$ so derivatization of nitrate groups does not inherently bias partitioning measurements toward the particle phase and does not impact the observed lack of correlation between $F_{P}$ and approximate vapor pressure or thermodynamic models (e.g. Figs. 2d and 4). The primary source of measurement bias therefore likely stems from the thermal decomposition of oligomers and hetero-oligomers, though this is a source of concern not only for this instrument, but for all chromatographic measurements given the reasonable comparison between these measurements and filters (discussed above). The observations are therefore discussed in the main text primarily with the context and understanding that formation of these low-volatility products is likely a significant process that modulates the measured partitioning of these compounds and that decomposition may be contributing to nearly all current and previous measurements of many individual tracer compounds.

Previous work ${ }^{3}$ explores in detail the precision and uncertainty of measurements made by SV-TAG, which is validated above by comparison to filter-based measurements of particle-phase concentrations. However, as the first measurements of $F_{P}$ in an ambient environment for unambiguously identified biogenic oxidation products, there is little existing data to validate the measurements of this instrument. In order to test the validity of these measurements, straightchain alkanoic acids are extremely valuable because (a) they are a series so the effect of increasing carbon number and therefore decreasing vapor pressure can be explored, (b) they have low solubility and no known pathways for the formation of low-volatility products that may impact observed measurements, and (c) they have been measured and reported before, ${ }^{17}$ providing a point of comparison. Unfortunately, due to relatively low concentrations in these environments coupled with high background contamination of these compounds, there are few periods when $n$-acids are confidently above level of quantification across the semi-volatile range. During the Amazon dry season measurements, however, there are a number of high alkanoic acid events. The partitioning of $n$-acids during these events (Fig. S4) is found to behave in a manner consistent with traditional absorptive partitioning. The relationship between the number of carbon atoms and the measured $F_{P}$ not only agrees qualitatively, but also quantitatively matches $F_{P}$ predicted based on vapor pressure. The observed, well-described relationship between decreasing vapor pressure and increasing $F_{P}$ within the $n$-acid series is consistent with observations by Yatavelli and co-workers using a different instrument. ${ }^{17}$ The influences of total organic mass as well as temperature are both observed in these measurements to agree well with the model, which is able to reasonably predict $F_{P}$ for nearly all observed $n$-acids across four separate events in Sept 2014.

\section{S1.3. Models}




\section{S1.3.1. Liquid water modeling}

At SOAS, ISORROPIA-II was run in the "forward" mode, in which gas-phase ammonia is added to the particle-phase ammonium measurements and allowed to re-partition. Due to the lack of ammonia measurements during IOP1 in the Amazon, the model for these data was run in "reverse" mode, constraining the measured ammonium mass to stay in the particle. This mode is less stable than "forward" mode and occasionally causes $\mathrm{pH}$ to become highly alkaline $(\mathrm{pH}>5)$, so periods with very high RH $(>99.5 \%)$ have been excluded from comparisons. The difference in calculated $\mathrm{pH}$ at IOP1 using "forward" vs "reverse" mode is slight, with a higher $\mathrm{pH}$ calculated from "reverse" mode. In both cases, a metastable phase state was assumed.

Total particle-phase liquid water is the sum of the "inorganic water" content calculated by ISORROPIA, $\mathrm{W}_{\mathrm{I}}$, and additional water due to uptake by the hygroscopic organic phase. At both sites, this "organic water" is calculated by estimating the organic hygroscopicity parameter, $\kappa$, from oxygen-to-carbon atomic ratio, and using it to estimate particle growth:

$$
W_{O}=\frac{V_{\text {org }}\{0.29(O: C)\}}{\left\{\frac{100}{R H \%}-1\right\}}
$$

The organic volume, $\mathrm{V}_{\text {org }}$, is the organic mass divided by its density (assumed here to be $1.4 \mathrm{~g} \mathrm{~cm}^{-3}$ ), the oxygen-to-carbon ratio, $\mathrm{O}: \mathrm{C}$, is calculated from the AMS, and relative humidity as a percent, $\mathrm{RH} \%$, is measured. The slope of the relationship between $\mathrm{O}: \mathrm{C}$ as calculated using the method of Aiken et al. ${ }^{9}$ and hygroscopicity is assumed to be $0.29 .{ }^{18}$ This value may vary somewhat between sites, but this is not expected to strongly influence the relative temporal variability in $\mathrm{W}_{\mathrm{O}}$ and therefore will not impact the conclusions of this manuscript.

\section{S1.3.2. Organic-only equilibrium partitioning models}

Particle fraction based on organic absorption is calculated from an organic absorptive equilibrium partitioning model, ${ }^{19,20}$, a common relatively simple model used by the atmospheric chemistry community. The estimated saturation concentration in units of $\left(\mu \mathrm{g} \mathrm{m}^{-3}\right), \mathrm{C}^{0}$, is calculated as:

$$
C^{0}=\frac{M W_{i} 10^{6} v_{P}}{760 R T}
$$

Which is a function of the molecular weight, MW, of compound $i$, the vapor pressure, $v_{P}$, the ideal gas constant in SI units of $\mathrm{J} \mathrm{K}^{-1} \mathrm{~mol}^{-1}$, $\mathrm{R}$, and the temperature in Kelvin, $\mathrm{T}$. Vapor pressure can be estimated using e.g., SIMPOL ${ }^{21}$ if the identity of the compound is known, or by chromatographic retention time. ${ }^{22,23}$ Lacking any chemical information about a given compound, vapor pressure can be estimated from retention time within approximately an order of magnitude. However, with even a small amount of chemical information (i.e. whether or not a compound is highly oxygenated), vapor pressure of a compound can be estimated to almost within the uncertainty of the values used to build the correlation. Figure S5 shows the relationships between alkane-based retention index, $t_{i}$, and the vapor pressure calculated by SIMPOL for 68 authentic standards that contain atmospherically relevant functional groups. The equations describing the fits of these relationships are: 
All unidentified compounds in this work are present only in derivatized samples and most correlate with a biogenic oxidation product that has multiple derivatized oxygen groups, so Eq. $\mathrm{S} 5$ is used in this work. From vapor pressure or saturation concentration, particle fraction, $F_{P}$, can be calculated from the total organic aerosol mass concentration, $\mathrm{C}_{\mathrm{OA}}$ :

$$
F_{P}=\left(1+\frac{\gamma C^{0}}{C_{O A}}\right)^{-1}
$$

This model relies on a number of assumptions that have not been observationally tested for individual compounds under ambient conditions, most importantly that a given compound is partitioning into a predominantly organic phase with similar chemical properties to the compound of interest and therefore behaves as an ideal solution in which the activity coefficient, $\gamma$, is equal to 1 . Solubility into an aqueous phase is not explicitly treated by this model due to high uncertainties (discussed below) though at these measurement sites particles are expected to consist of a single organic-rich aqueous phase due to highly oxygenated organic mass and high relative humidity.

\section{S1.3.3. Inclusion of solubility in absorptive equilibrium partitioning models}

Most BVOC oxidation products are expected to be relatively soluble owing to their high oxygen content, so a complete model of partitioning should therefore contain explicit parameterization of solubility. In most models this takes the form of a Henry's law constant, $H$, with units $\mathrm{M} \mathrm{atm}^{-1}$. However, several group contribution methods exist to estimate this parameter for a given compound, and estimation for many known tracers requires extrapolation beyond the original bounds of the models. Estimated Henry's law constants consequently often differ by several orders of magnitude, so explicit inclusion of solubility into an equilibrium partitioning model for an individual compound is infeasible.

The effect of this uncertainty is demonstrated using the framework of Wania and coworkers, ${ }^{24}$ which assumes absorptive equilibrium partitioning into two separate liquid phases one aqueous and one organic - and is used here to approximately model the effects of vapor pressure and solubility on $F_{P}$. In this model, partitioning into the organic phase is combined with partitioning into an aqueous phase based on an estimated Henry's law constant, $H_{\text {est }}$ (here in units of $\left.\mathrm{M} \mathrm{atm}^{-1}\right)$ :

$$
F_{P}=1-\left(1+H_{e s t} \times W_{t o t} \frac{R \prime T}{10^{12}}+\frac{C_{O A}}{C^{0}}\right)^{-1}
$$

which is dependent on total particle-phase liquid water, $W_{t o t}$, and temperature, $\mathrm{T}-$ both explicitly and implicitly in the Henry's law constant, which decreases with temperature. The ideal gas constant, $R$, is in the non-SI units of $0.082 \mathrm{~L} \mathrm{~atm} \mathrm{~K}^{-1} \mathrm{~mol}^{-1}$.

In Fig. S6, predicted $F_{P}$ is shown for the median particle during SV-TAG measurements at SOAS (liquid water: $7.7 \mu \mathrm{g} \mathrm{m}^{-3}$, organic mass: $4.5 \mu \mathrm{g} \mathrm{m}^{-3}$ ). Parameters for solubility and vapor pressure are calculated using five different widely available, commonly used estimation methods: SIMPOL ${ }^{21}$, SPARC $^{25}$, EVAPORATION ${ }^{26}$, the EPI suite ${ }^{27}$, and GROMHE ${ }^{28}$. The $\mathrm{x}-$ 
and y-axis are shown across the same span to clearly demonstrate that that vapor pressure is far less uncertain than the Henry's law constant for any given compound - in this case 2methylerythritol, which is used as an example in Fig. 2c,d. Available methods for the estimation of the Henry's law constant for this compound differ by approximately 6 orders of magnitude, spanning the range of completely soluble to completely insoluble at these liquid water concentrations. On the other hand, most modern, complex group contribution methods differ by less than an order of magnitude in vapor pressure, though even this uncertainty sits precisely in the range expected to strongly influence partitioning.

In Table $\mathrm{S} 1$, predicted $F_{P}$ from this model is compared to observations for 2methylerythritol in the cases of each of these estimation techniques. For each data point, the partitioning space shown in Fig. S6 is redrawn, and the predicted $F_{P}$ is calculated. All combinations of estimated vapor pressure and Henry's law constant yield substantial bias in the model $(30$ to $98 \%)$ and poor correlation with observations $\left(r^{2}<0.15\right)$. Estimating solubility from GROMHE predicts this compound to be nearly always in the particle-phase, thus overpredicting $F_{P}$ while the estimation from the EPI suite, conversely suggests that solubility is not a factor for 2-methylerythritol and $F_{P}$ is predicted solely based on organic absorption. The Henry's law constant estimated by SPARC makes 2-methylerythritol semi-volatile with respect to solubility, yielding the closest predictions to observations. However, the temporal variability is still poorly described $\left(r^{2}=0.14\right)$.

The explicit treatment of these two processes - absorption into organic mass and absorption into particle-phase liquid water - is prevented by the high uncertainties in solubility parameters, but a similar model framework can be used to approximate the behavior of a single liquid phase with a composition that is a mixture of organics and water, such as is expected in these measurement campaigns. In these cases, $F_{P}$ is modeled by ignoring vapor pressure and instead assuming absorptive equilibrium partitioning into a single phase consisting of the mass of both organics and liquid water:

$$
F_{P}=1-\left(1+H_{m i x, e s t} \times\left(W_{t o t}+C_{O A}\right) \times \frac{R^{\prime} T}{10^{12}}\right)^{-1}
$$

As an example, the estimated Henry's law constant for the mixture, $H_{m i x}$, was estimated by SPARC for representative solvents: a mixture of water and "generic organics", a mixture of water and methoxyethanol, and pure methoxyethanol. Methoxyethanol was chosen as a solvent based on its similar oxygen-to-carbon ratio to observed organic phase and its multi-functionality, including oxygen both with and without hydrogen bonding. The results of these cases are shown in Table S2. Though partitioning into a mixture of water and methoxyethanol has the lowest difference between the model and observations, the variability is not captured. Tuning solubility parameters based on observed $F_{P}$ to minimize the bias is also found to have a correlation of only $\mathrm{r}^{2}=0.13$ (Table S2), which is not substantially improved by modifying the assumed temperature dependence, $a$. Examples are shown in Fig. S7 for absorption into organics based on (a) SIMPOL vapor pressure, (b) optimized absorption into a mixed aqueous-organic phase, and (c) optimized absorption into organic mass only. It is clear from all of the cases presented in Tables S1 and S2 that solubility estimation is too uncertain to accurately include in models of individual tracers, and even when constrained by observations can explain only a small fraction of the observed variability. Model optimization is therefore possible when constrained by observations, allowing for the calculation of an effective Henry's law constant (see Sect. S1.3.4), but these 
optimized parameters can only decrease discrepenacies between observed and expected average $F_{P}$, they do not reconcile observed variability.

\section{S1.3.4. Estimating changes in equilibrium partitioning in new environments}

Though explicit inclusion of solubility in modeling $F_{P}$ of individual compounds is stymied by high uncertainty, the expected change in $F_{P}$ directly observed at a reference condition (e.g. a given average measurement site) can be estimated under new conditions using assumptions of a single mixed or pure organic phase.

As discussed above, under conditions dominated by compounds partitioning into an organic phase, organic absorptive equilibrium partitioning can be estimated from vapor pressure (Eqs. S2 and S6). Observed partitioning can therefore be used to calculate an effective saturation concentration, $C_{e f f}^{0}$, that describes the organic mass loading at which a compound is evenly split between the gas and particle phase under the reference condition:

$$
C_{e f f}^{0}\left(T, C_{O A}\right)=\left(F_{P}^{-1}-1\right) C_{O A}
$$

$F_{P}$ can be theoretically predicted in a new environment by adjusting for $\mathrm{C}_{\mathrm{OA}}$ and temperature and combining Eqs. S6 and S9:

$$
F_{P}=\left(1+\frac{C_{e f f}^{0}\left(T, C_{O A}\right)}{C_{O A}}\right)^{-1}
$$

While the relationship with total organic concentration is clear, the influence of temperature is less obvious due to the temperature effect in vapor pressure. To better model this relationship, the estimated saturation concentration, $C_{e f f}^{0}$, was calculated for three common but chemically different BVOC oxidation products (Fig. S8) using SIMPOL. The relationship between $\mathrm{C}^{0}$ and temperature - a function of enthalpy of vaporization - is found to be similar for all three compounds across the ambient temperature range, so an average slope of 0.055 in $\log \left(\mathrm{C}^{0}\right)$ was used. With this value, particle fraction in a new environment or at a new time, $F_{P}(\mathrm{t})$ can be predicted from a previous measurement at a reference time, ref, as:

$$
F_{P}=\left(1+\frac{\left\{10^{0.055\left(T-T^{r e f}\right)}\right\}\left\{\left(F_{P}^{r e f}\right)^{-1}-1\right\}\left\{C_{O A}^{r e f}\right\}}{C_{O A}}\right)^{-1}
$$

Equation S12 models the impact of temperature and total organic mass on the partitioning of a compound. Similarly, solubility can be included by calculation of an empirical effective Henry's law constant, $H_{\text {eff }}$, at the reference condition by rearranging Eq. S8:

$$
H_{\text {mix }, \text { eff }}=\frac{\left(1-F_{P}\right)^{-1}-1}{R^{\prime} T\left(W_{t o t}+C_{O A}\right) 10^{-12}}
$$

Empirical observation of $H_{\text {mix, eff }}$ is necessarily based on the assumption of a single organic-rich aqueous phase (Eq. S8) - assumption of separation between two separate organic and aqueous phases requires simultaneous calculation of $C_{e f f}^{0}$ and $H_{\text {eff }}$ and is therefore an unconstrained equation. This effective Henry's law constant can (similarly to Eq. S11) be used to 
estimate the effects of changes in temperature, organic mass, and particle-phase liquid water mass on partitioning:

$$
F_{P}=1-\left(1+\frac{\left\{10^{-a\left(T-T^{r e f}\right)}\right\}\left\{\left(1-F_{P}^{r e f}\right)^{-1}-1\right\}^{-1}\left\{W_{t o t}+C_{O A}\right\}}{\left(W_{t o t}^{r e f}+C_{O A}^{r e f}\right)}\right)^{-1}
$$

The influence of temperature on Henry's law, $a$, is compound dependent and approximated in previous work as 0.03 , though a range of 0.03 to $0.3 \log$ units per degree Celsius is reasonable based on observed enthalpies of vaporization. ${ }^{28}$ In this work, 0.055 is used so that for a dry particle $\left(\mathrm{W}_{\text {tot }}=0\right)$, Eqs. S11 and S13 are equivalent and $F_{P}$ calculated through either method is equal. These two empirical effective uptake parameters, $C_{e f f}^{0}$ and $H_{m i x, e f f}$, both describe thermodynamic equilibrium absorption into a single liquid phase, differing only in their assumption of solubility of organics into the particle-phase liquid water.

These empirical uptake parameters can be used to study the expected effect of atmospheric state and particle composition on partitioning based on absorptive equilibrium partitioning. To understand how the observed changes in $F_{P}$ between measurement sites compare to expectations due to changes in particle composition and temperature (i.e. dashed lines in Fig. $4 \mathrm{~b}), H_{\text {mix,eff }}$ is used based on the assumption that there is only a single aqueous liquid phase into which a compound can partition and solubility of these compounds is non-negligible. However, as demonstrated by Figs. 3 and S8, the relationships described by Eqs. S11 and S13 do not capture a large amount of the observed temporal variability, even within a campaign. Consequently, observed effective uptake parameters provide a means to compare observations between sites to expectations based on differences in particle composition in an average sense, but these parameters are not necessarily expected to yield reasonable predictions. Nevertheless, calculated effective uptake parameters are provided in this work for comparison of these reported measurements with future studies. The comparison between observations and this model are discussed in the main text and below.

\section{S2. Supporting results}

\section{S2.1. Particle composition and water content}

Average particle composition during SOAS, in the southeastern U.S., and during the Amazon wet season (IOP1) is shown in Fig. S9a. The average ratio of organics to inorganics is approximately twice as high in the Amazon wet season as in the southeastern U.S. site, which substantially influences the particle-phase liquid water content at each site. During IOP1, organic water comprises a majority of the particle mass, and total water usually accounts for more than half the particle mass (Fig. 10b). Water is also an important constituent at SOAS, though to a somewhat lesser degree than during IOP1. In the southeastern U.S. measurements, organic water is approximately one-third of the average total water, consistent with previous work. ${ }^{29}$ Absolute concentrations are higher in this work than reported in previous work, ${ }^{30}$ due to slight differences in measured relative humidity, which has a very large effect on $\mathrm{W}_{\text {tot. }}{ }^{29}$

To validate the results of thermodynamic modeling such as ISORROPIA, gas-phase measurements of $\mathrm{NH}_{3}$ of $\mathrm{HNO}_{3}$ are typically compared to modeled values to determine the 
ability of the model to reproduce observations. These compounds were not measured during GoAmazon2014/5, so the model values are explored here through comparison to SOAS model results. As observed by Hennigan et al. ${ }^{31}$ for other locations, the addition of ammonia to the ISORROPIA model at SOAS does not have a strong effect calculated on particle-phase liquid water (Fig. S10), so the role of water can reasonably be explored in the Amazon measurements based on this model.

Diurnal profiles of particle-phase organic mass, temperature, and relative humidity are provided in Fig. S11 to provide context for observed patterns in partition (e.g. Figs. 2 and 3).

\section{S2.2 Observed variability in partitioning}

\section{S2.2.1. Diurnal variability}

Expanded versions of Figs. 1c and d are provided as Fig. S12 to provide the reader with a more detailed view of the data.

The impact of particle composition variability on $F_{P}$ predicted by absorptive partitioning can be explored using Eqs. S11 and S13. The observed normalized diurnal variability shown in Fig. 3 is compared in Fig. S13 to the median diurnal variability expected for a partitioned compound observed at SOAS or in the Amazon wet season. As discussed in the main text, the qualitative shape is not unexpected, with a general decrease in $F_{P}$ observed during the day as would be predicted based on temperature changes (though contrary to the daytime maximum in OA mass at IOP1). Note that this comparison only captures relative diurnal variability, not absolute predicted $F_{P}$ which is generally observed to be substantially higher than predicted based on vapor pressure. The predicted diurnal variability depends strongly on whether uptake is assumed to depend only on organic aerosol mass based on $C_{e f f}^{0}$, or also on particle-phase liquid water based on $H_{\text {eff. }}$. In either case, observed variability falls at most times outside or at the edge of the interquartile range of the observations and has a different pattern. Due to strong diurnal variability in $\mathrm{W}_{\text {tot }}$, predicted variability during IOP1 is substantially stronger than observed when $\mathrm{H}_{\text {eff }}$ is used as the effect uptake parameter. The conclusion that equilibrium partitioning based on vapor pressure and solubility is not the sole driver of partitioning in these environments is supported by the observations in Fig. 2a,b that different compounds vary between campaigns in different ways, and the conclusion from Figs. 4a, S6, and 8 that a simple absorptive equilibrium partitioning model fails to capture the observed temporal variability of some compounds.

\section{S2.2.2. Compound-to-compound variability}

In Fig. S14, isomers within a compound class are found to have closely correlated particle fractions, so partitioning for these compounds is likely driven by the same processes. Though 2-methylerythritol has a consistently higher particle fraction than 2-methylthreitol by $\sim 50 \%$, the correlation between them is very high $\left(\mathrm{r}^{2}=0.86\right)$, and the best linear fit has an intercept near the origin (Fig. S14a). The comparison for two $\mathrm{C}_{5}$ alkene triols (Fig. S14b) is very similar, with a high correlation coefficient $\left(\mathrm{r}^{2}=0.84\right)$ and in this case similar $F_{P}$. However, as shown in Fig. 2c, comparing 2-methylerythritol to 3-methyl-2,3,4-trihydroxy-1-butene finds very little correlation in their partitioning variability, despite similar average $F_{P}$ and similar functionality. Variability in particle-phase liquid water, temperature, or other changes in particle 
composition are expected to impact partitioning of these compounds in a similar manner, so simple equilibrium partitioning based on vapor pressure or solubility does not adequately describe these dominant compounds. The comparison across compound classes is expanded in Fig. S15 to two compounds from different biogenic precursors for both SOAS and GoAmazon2014/5 IOP1. Given their chemical differences (tetrahydroxy versus triacid), it is perhaps not unexpected that there is little or no correlation of $F_{P}$.

Though $\alpha$-pinene oxidation products are observed to have average $F_{P}$ values reasonably well described by organics-only absorptive equilibrium partitioning (Fig. S16), variability of $F_{P}$ between species - even with similar chemical structures and similar average $F_{P}$ - is poorly correlated (Fig. S17). It is difficult to draw clear trends out of these examples as their differences in functionality and Henry's law coefficients (Table S3) are in most cases minor. Tricarboxylic acid (compound "L" in Fig. 4 and Tables S4-7) differs from 3-methyl-1,2,3-butane tricarboxylic acid ("M") by only two methyl groups and contain the same number of carboxylic acid groups, yet the correlation is poor (S14b). This may provide some indication that steric hindrance plays a role by preventing some of the reactions that form low-volatility products, but verification of this hypothesis will require unambiguous structural identification of many more biogenic oxidation products. These two compounds have negligible difference in their retention time, and the difference in Henry's law constant as estimated by SPARC is less than half an order of magnitude for these compounds as well as for the compounds shown in Fig. S17a, so absorptive equilibrium partitioning is unlikely to explain observed differences. Though still poor, the closest correlations are those of 3-hydroxyglutaric acid ("H") with two other 3-monosubstituted pentanedioic acids: 3-acetyl pentanedioic acid ("I") and tricarballylic acid (c,d), though the correlation between these latter two is that shown in Fig. S17a and is poor. Pinic acid ("J") shows almost no correlation with all four of the compounds compared in Figs. S17a-d (example shown in Fig. S17e), but this may be due to the difference in number of oxygenated functional groups or differences in Henry's law constant (much lower for pinic acid). Note that the retention time for pinic acid sits in the middle of these other four compounds, further demonstrating that vapor pressure is not driving the differences in observed partitioning. Pinonic acid ("F") is the only identified monoterpene oxidation product discussed in this work that partitions qualitatively (though not quantitatively) similarly to pinic acid is, (Fig. S17f) and similarly has 2 oxygenated functional groups and relatively low Henry's law constant. These comparisons do not provide strong evidence for a dominant reaction pathway but do support the other observations in this work indicating chemistry-driven partitioning that is not well described by equilibrium uptake based on external environmental properties.

\section{S2.2.3. Inter-campaign variability}

The comparison between observed Amazon wet season and the other two measurement campaigns, shown on average in Fig. 4b, is split into day and night in Fig. S18. These comparisons lead to roughly the same conclusions discussed in the main text: that the variability in $F_{P}$ observed between campaigns is less than predicted based on their differences in temperature, particle-phase organic mass concentrations, and particle-phase liquid water mass. Though a stronger difference between campaigns is observed at night, a stronger difference is also expected based on compositional differences. Note that predicted $F_{P}$ based on absorptive equilibrium partitioning into a combined organics-plus-aqueous phase better captures differences between campaigns than basing partitioning solely on organic mass. The deviation of the 
observations at each site from that predicted by an adjustment for water and organic mass and temperature is shown in Fig. S19. When comparing daily averages as in Fig. 4b, absolute deviation for partitioned compounds is typically greater than 0.20 , with higher differences observed for compounds with higher gas-phase fractions, resulting in differences of over $50 \%$ in $F_{P}$ for nearly all compounds that have a particle fraction of less than half. The relative difference in the observed $F_{P}$ in the Amazon dry season (IOP2) and that predicted from IOP1 using Eq. S13 is compared in Fig. S19a to the difference between observed $F_{P}$ in IOP2 and observed $F_{P}$ in IOP1.

Observations from IOP1 are typically lower than observed IOP2 $F_{P}$, while predictions from changes in temperature and organic mass yield an overestimate of $F_{P}$. However, the absolute difference in $F_{P}$ is smaller between observations than when predicting $F_{P}$ based on measured effective Henry's law constant. For mostly particle-phase compounds, there is little difference between these two approximation techniques: each is on average $\sim 20 \%$ different from observations. However, as gas-phase fraction increases, the ability to capture observed $F_{P}$ by adjusting IOP1 observations quickly yields high relative error. The absolute difference between observed $F_{P}$ at IOP1 and IOP2 is almost always less than 0.20 . Assuming a constant $F_{P}$ between these campaigns therefore leads in most cases to lower relative error for partitioned compounds than modeling $F_{P}$ based on absorptive partitioning using a measures effective saturation concentration. This is consistent with observed partitioning being influenced strongly by nonequilibrium effects that are not captured by thermodynamic equilibrium models.

\section{S2.3. Average partitioning values}

As discussed in the main text and above, the average observed $F_{P}$ for a given BVOC oxidation product is relatively consistent across the measured environments. Though the observed temporal variability cannot yet be fully explained due to the complex and concurrent influencing factors, the relative stability between sites provides an improved means to model these tracers under typical ambient conditions. Table S4 provides the average daytime and nighttime $F_{P}$ values during each measurement campaign for 13 known compounds, and an overall average across all campaigns. The average absolute change in $F_{P}$ between day and night is also shown, as this diurnal trend is relatively stable between sites, with tracers preferentially in the particle-phase at night. The average effective uptake parameters used to model the expected influence of particle composition on $F_{P}$ are provided in Tables S5 and S6. Effective saturation concentration (Table S5) is calculated from $F_{P}$ for each campaign based on organic mass and temperature (Eq. S11), while effective Henry's law constant (Table S6) also includes particlephase liquid water (Eq. S13). For all compounds not identified, values of $F_{P}$ during IOP1 (data in Fig. 4a) are provided in Table S7, identified by alkane-based retention index and ion used for chromatographic peak integration. To provide some indication of whether an unknown compound is likely a BVOC oxidation product, the correlation between each unknown compound with each known compound was calculated. The highest correlation coefficient, $r$, within each category of known compound - isoprene oxidation products, pinene oxidation products, and levoglucosan, a tracer for biomass burning - is shown in Table S7, with the highest of these three coefficients used to categorize each unknown compound by precursor. Points with $\mathrm{r}<0.6$ for all compounds remain uncategorized. 


\section{References}

(1) Kuhn, U.; Ganzeveld, L.; Thielmann, a.; Dindorf, T.; Schebeske, G.; Welling, M.; Sciare, J.; Roberts, G.; Meixner, F. X.; Kesselmeier, J.; et al. Impact of Manaus City on the Amazon Green Ocean atmosphere: Ozone production, precursor sensitivity and aerosol load. Atmos. Chem. Phys. 2010, 10 (19), 9251-9282.

(2) Trebs, I.; Mayol-Bracero, O. L.; Pauliquevis, T.; Kuhn, U.; Sander, R.; Ganzeveld, L.; Meixner, F. X.; Kesselmeier, J.; Artaxo, P.; Andreae, M. O. Impact of the Manaus urban plume on trace gas mixing ratios near the surface in the Amazon Basin: Implications for the NO-NO2-O 3 photostationary state and peroxy radical levels. J. Geophys. Res. Atmos. 2012, $117(5), 1-16$.

(3) Isaacman, G.; Kreisberg, N. M.; Yee, L. D.; Worton, D. R.; Arthur, W. H. On-line derivatization for hourly measurements of gas- and particle-phase semi-volatile oxygenated organic compounds by Thermal desorption Aerosol Gas chromatography ( SV-TAG ). Atmos. Meas. Tech. 2014, 7, 4417-4429.

(4) Zhao, Y.; Kreisberg, N. M.; Worton, D. R.; Teng, A. P.; Hering, S. V; Goldstein, A. H. Development of an In Situ Thermal Desorption Gas Chromatography Instrument for Quantifying Atmospheric Semi-Volatile Organic Compounds. Aerosol Sci. Technol. 2013, 47 (3), 258-266.

(5) Isaacman-VanWertz, G.; Sueper, D. TERN: TAG ExploreR and iNtegration https://sites.google.com/site/terninigor/.

(6) Budisulistiorini, S. H.; Li, X.; Bairai, S. T.; Renfro, J.; Liu, Y.; Liu, Y. J.; McKinney, K. a.; Martin, S. T.; McNeill, V. F.; Pye, H. O. T.; et al. Examining the effects of anthropogenic emissions on isoprene-derived secondary organic aerosol formation during the 2013 Southern Oxidant and Aerosol Study (SOAS) at the Look Rock, Tennessee, ground site. Atmos. Chem. Phys. Discuss. 2015, 15 (5), 7365-7417.

(7) Jaoui, M.; Kleindienst, T. E.; Lewandowski, M.; Offenberg, J. H.; Edney, E. O. Identification and quantification of aerosol polar oxygenated compounds bearing carboxylic or hydroxyl groups. 2. Organic tracer compounds from monoterpenes. Environ. Sci. Technol. 2005, 39 (15), 5661-5673.

(8) DeCarlo, P. F.; Kimmel, J. R.; Trimborn, A.; Northway, M. J.; Jayne, J. T.; Aiken, A. C.; Gonin, M.; Fuhrer, K.; Horvath, T.; Docherty, K. S.; et al. Field-Deployable, HighResolution, Time-of-Flight Aerosol Mass Spectrometer. Anal. Chem. 2006, 78 (24), 82818289.

(9) Aiken, A. C.; DeCarlo, P. F.; Kroll, J. H.; Worsnop, D. R.; Huffman, J. A.; Docherty, K. S.; Ulbrich, I. M.; Mohr, C.; Kimmel, J. R.; Sueper, D.; et al. O/C and OM/OC Ratios of Primary, Secondary, and Ambient Organic Aerosols with High-Resolution Time-of-Flight Aerosol Mass Spectrometry. Environ. Sci. Technol. 2008, 42 (12), 4478-4485. 
(10) Canagaratna, M. R.; Jimenez, J.-L.; Kroll, J. H.; Chen, Q.; Kessler, S. H.; Massoli, P.; Hildebrandt Ruiz, L.; Fortner, E.; Williams, L. R.; Wilson, K. R.; et al. Elemental ratio measurements of organic compounds using aerosol mass spectrometry: characterization, improved calibration, and implications. Atmos. Chem. Phys. Discuss. 2015, 15, 253-272.

(11) Liu, P. S. K.; Deng, R.; Smith, K. a.; Williams, L. R.; Jayne, J. T.; Canagaratna, M. R.; Moore, K.; Onasch, T. B.; Worsnop, D. R.; Deshler, T. Transmission Efficiency of an Aerodynamic Focusing Lens System: Comparison of Model Calculations and Laboratory Measurements for the Aerodyne Aerosol Mass Spectrometer. Aerosol Sci. Technol. 2007, $41(8), 721-733$.

(12) Sueper, D. ToF-AMS Analysis Software. 2012.

(13) Middlebrook, A. M.; Bahreini, R.; Jimenez, J.-L.; Canagaratna, M. R. Evaluation of Composition-Dependent Collection Efficiencies for the Aerodyne Aerosol Mass Spectrometer using Field Data. Aerosol Sci. Technol. 2012, 46 (3), 258-271.

(14) Saylor, R. D.; Edgerton, E. S.; Hartsell, B. E.; Baumann, K.; Hansen, D. A. Continuous gaseous and total ammonia measurements from the southeastern aerosol research and characterization (SEARCH) study. Atmos. Environ. 2010, 44 (38), 4994-5004.

(15) Turpin, B. J.; Saxena, P.; Andrews, E. Measuring and simulating particulate organics in the atmosphere : problems and prospects. Atmos. Environ. 2000, 34, 2983-3013.

(16) Kroll, J. H.; Seinfeld, J. H. Chemistry of secondary organic aerosol: Formation and evolution of low-volatility organics in the atmosphere. Atmos. Environ. 2008, 42 (16), 3593-3624.

(17) Yatavelli, R. L. N.; Stark, H.; Thompson, S. L.; Kimmel, J. R.; Cubison, M. J.; Day, D. A.; Campuzano-Jost, P.; Palm, B. B.; Hodzic, A.; Thornton, J. A.; et al. Semicontinuous measurements of gas-particle partitioning of organic acids in a ponderosa pine forest using a MOVI-HRToF-CIMS. Atmos. Chem. Phys. 2014, 14 (3), 1527-1546.

(18) Massoli, P.; Lambe, a. T.; Ahern, a. T.; Williams, L. R.; Ehn, M.; Mikkilä, J.; Canagaratna, M. R.; Brune, W. H.; Onasch, T. B.; Jayne, J. T.; et al. Relationship between aerosol oxidation level and hygroscopic properties of laboratory generated secondary organic aerosol (SOA) particles. Geophys. Res. Lett. 2010, 37 (24), 1-5.

(19) Pankow, J. F. An absorption model of gas/particle partitioning of organic compounds in the atmosphere. Atmos. Environ. 1994, 28 (2), 185-188.

(20) Odum, J. R.; Hoffmann, T.; Bowman, F.; Collins, D. R.; Flagan, R. C.; Seinfeld, J. H. Gas/particle partitioning and secondary organic aerosol yields. Environ. Sci. Technol. 1996, 30, 2580-2585. 
(21) Pankow, J. F.; Asher, W. E. SIMPOL.1: a simple group contribution method for predicting vapor pressures and enthalpies of vaporization of multifunctional organic compounds. Atmos. Chem. Phys. 2008, 8, 2773-2796.

(22) Hinckley, D. a.; Bidleman, T. F.; Foreman, W. T.; Tuschall, J. R. Determination of vapor pressures for nonpolar and semipolar organic compounds from gas chromatograhic retention data. J. Chem. Eng. Data 1990, 35 (3), 232-237.

(23) Isaacman, G.; Worton, D. R.; Kreisberg, N. M.; Hennigan, C. J.; Teng, A. P.; Hering, S. V; Robinson, A. L.; Donahue, N. M.; Goldstein, A. H. Understanding evolution of product composition and volatility distribution through in-situ GC $\times$ GC analysis: a case study of longifolene ozonolysis. Atmos. Chem. Phys. 2011, 11 (11), 5335-5346.

(24) Wania, F.; Lei, Y. D.; Wang, C.; Abbatt, J. P. D.; Goss, K.-U. Using the chemical equilibrium partitioning space to explore factors influencing the phase distribution of compounds involved in secondary organic aerosol formation. Atmos. Chem. Phys. 2015, 15 (6), 3395-3412.

(25) Hilal, S. H.; Karickhoff, S. W.; Carreira, L. a. Prediction of the solubility, activity coefficient and liquid/liquid partition coefficient of organic compounds. QSAR Comb. Sci. 2004, 23 (9), 709-720.

(26) Compernolle, S.; Ceulemans, K.; Müller, J.-F. EVAPORATION: a new vapour pressure estimation methodfor organic molecules including non-additivity and intramolecular interactions. Atmos. Chem. Phys. 2011, 11 (18), 9431-9450.

(27) US EPA. Estimation Program Interface (EPI) Suite. 2008.

(28) Raventos-Duran, T.; Camredon, M.; Valorso, R.; Mouchel-Vallon, C.; Aumont, B. Structure-activity relationships to estimate the effective Henry's law constants of organics of atmospheric interest. Atmos. Chem. Phys. 2010, 10 (16), 7643-7654.

(29) Guo, H.; Xu, L.; Bougiatioti, a.; Cerully, K. M.; Capps, S. L.; Hite, J. R.; Carlton, a. G.; Lee, S.-H.; Bergin, M. H.; Ng, N. L.; et al. Particle water and pH in the southeastern United States. Atmos. Chem. Phys. Discuss. 2014, 14 (19), 27143-27193.

(30) Xu, L.; Guo, H.; Boyd, C. M.; Klein, M.; Bougiatioti, A.; Cerully, K. M.; Hite, J. R.; Isaacman-VanWertz, G.; Kreisberg, N. M.; Knote, C.; et al. Effects of anthropogenic emissions on aerosol formation from isoprene and monoterpenes in the southeastern United States. Proc. Natl. Acad. Sci. U. S. A. 2015, 112 (1), 37-42.

(31) Hennigan, C. J.; Izumi, J.; Sullivan, a. P.; Weber, R. J.; Nenes, a. A critical evaluation of proxy methods used to estimate the acidity of atmospheric particles. Atmos. Chem. Phys. 2015, 15 (5), 2775-2790. 
742

743
(32) Stockli, R.; Vermote, E.; Saleous, N.; Simmon, R.; Herring, D. The Blue Marble Next Generation - A true color earth dataset including seasonal dynamics from MODIS. NASA Earth Obs. 2005.

(33) Arino, O.; Ramos Perez, J. J.; Kalogirou, V.; Bontemps, S.; Defourney, P.; Van Bogaert, E. Global Land Cover Map for 2009 (GlobCover 2009). Eur. Sp. Agency Univ. Cathol. Louvain 2012. 


\section{Figures and Tables}

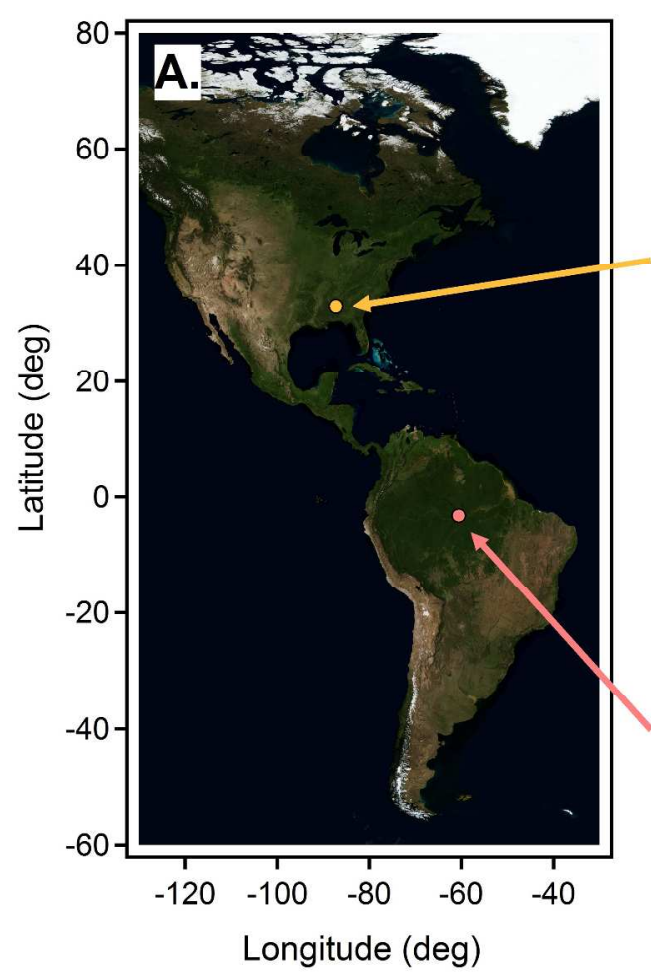

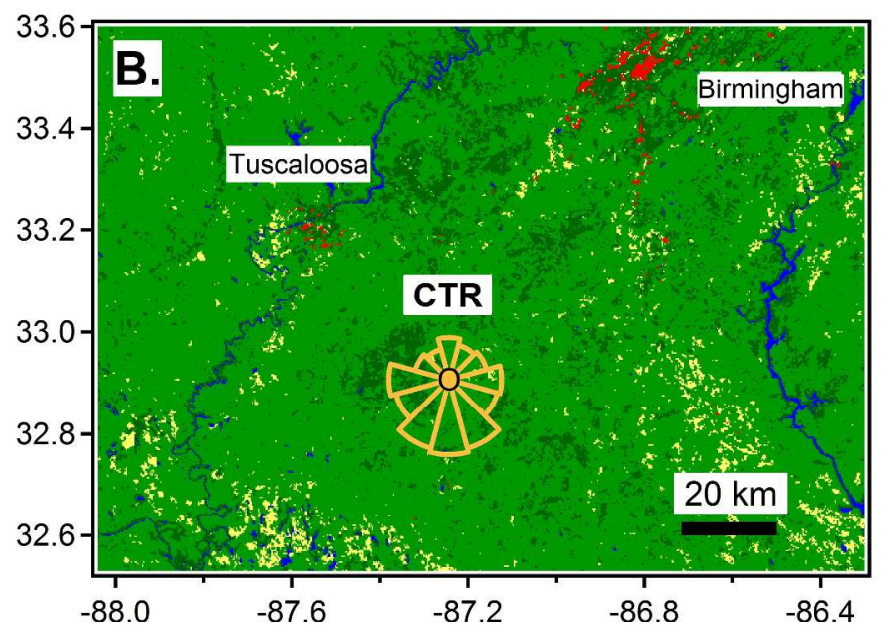

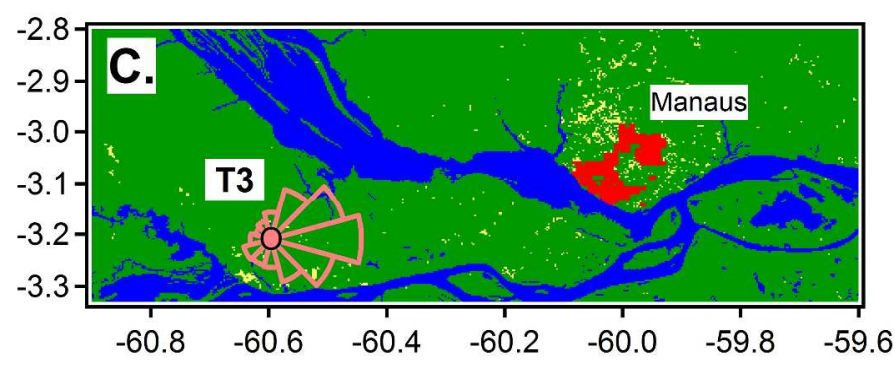

746

747

748

749

750

751

752

753

Fig. S1. Location of measurements from (A) a hemispheric perspective in natural color ${ }^{32}$, and a close-up of the landcover surrounding (B) SOAS measurements at the CTR site and (C) GoAmazon2014/5 measurements at the T3 site. A windrose is shown at both groundsites (IOP1 data used for panel C). Major nearby urban areas are labeled. Land is colored by the majority of its landcover based on $0.3 \mathrm{~km}$ x $0.3 \mathrm{~km}$ data from GlobCover $2009^{33}$ : broadleaf vegetation in light green, coniferous vegetation in dark green, cropland in yellow, urban in red, water in blue. 


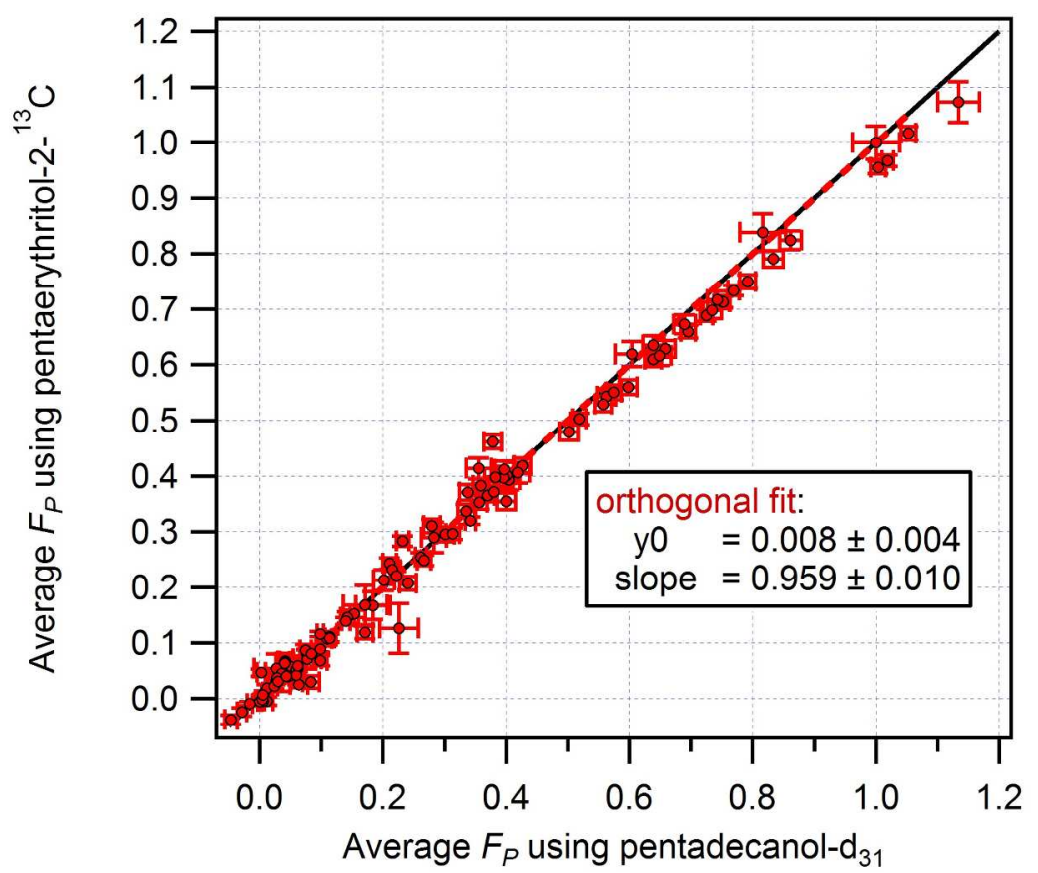

Fig. S2. Comparison of $F_{P}$ for all observed compounds in GoAmazon2014/5 IOP1 using the most and least oxygenated internal standard available to correct for run-to-run variability. The 757 orthogonal least squares squares fit assuming errors in both variables. 

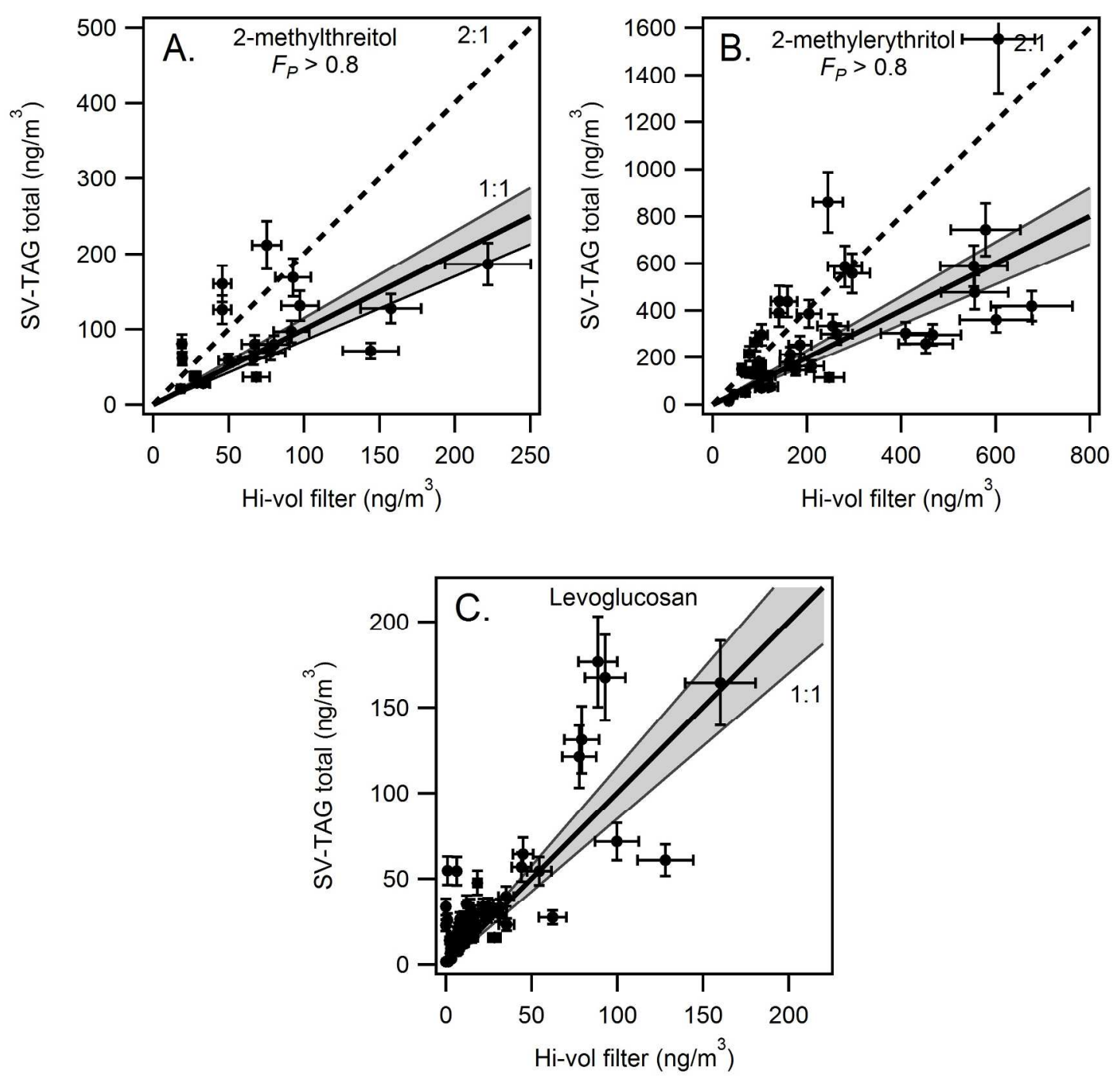

760 Fig. S3. Comparison of concentrations measured by SV-TAG and through filter collection and 761 extraction for (A) 2-methylthreitol, (B) 2-methylerythritol, and (C) levoglucosan. Solid line is $762 \quad 1: 1$ with $+/-15 \%$ in shaded gray. Dashed line is $2: 1$. 

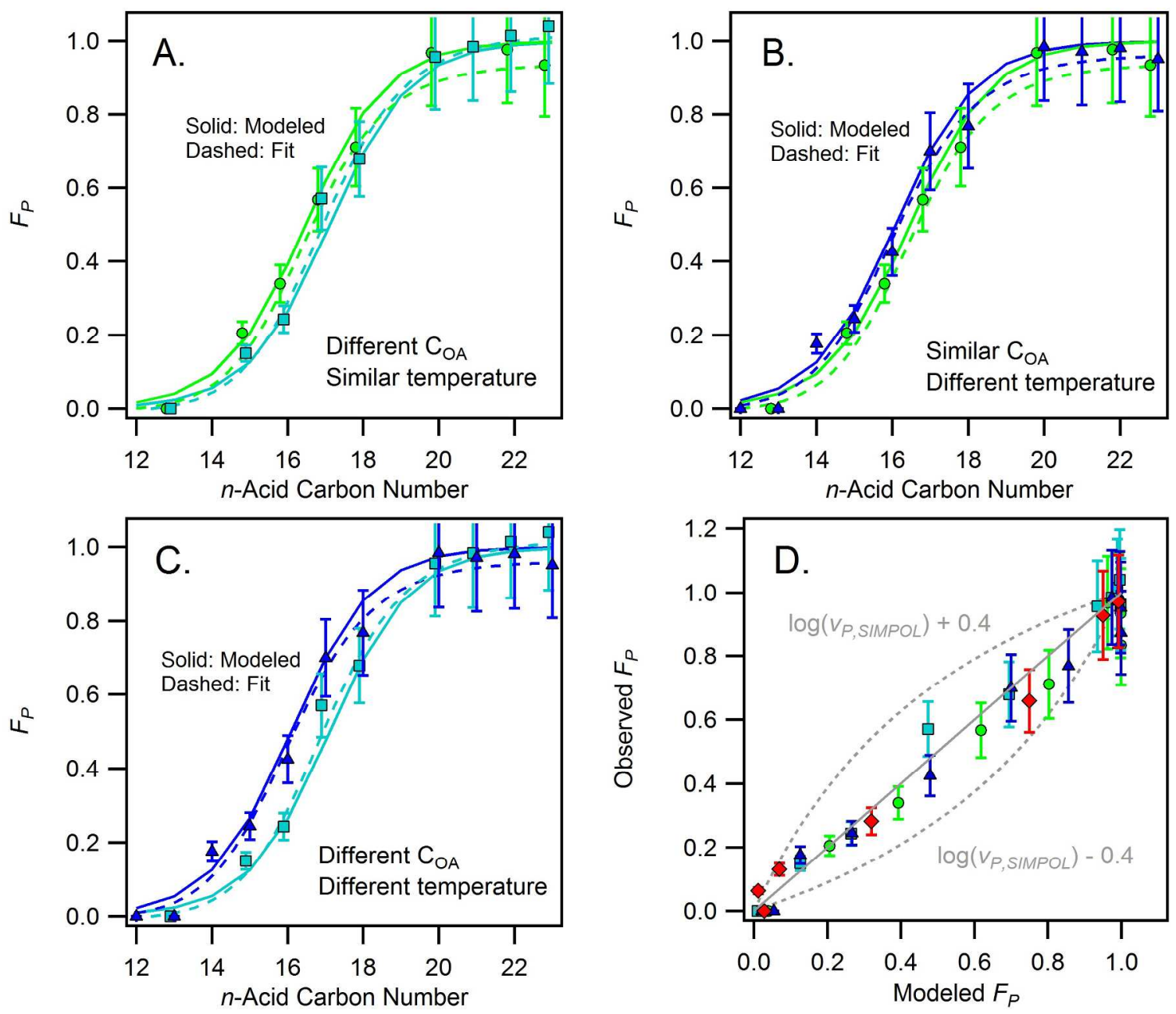
Sept. 3 event: $15 \mu \mathrm{g} \mathrm{m}^{-3}, 26{ }^{\circ} \mathrm{C}$

Sept. 14 event: $28 \mu \mathrm{g} \mathrm{m}^{-3}, 24^{\circ} \mathrm{C}$ Sept. 22 event: $17 \mu \mathrm{g} \mathrm{m}^{-3}, 25^{\circ} \mathrm{C}$

765

766

767

768

769

770

771

772
Fig. S4. Comparison of observed $F_{P}$ of n-alkanoic acids to an organic absorption equilibrium partitioning model. In (A) and (B), the effects of organic loading and temperature are explored by pairing events during GoAmazon2014/5 IOP2 in which one of these variables is approximately constant, while (C) demonstrates the ability of a simple absorptive partitioning model to match measurements in two somewhat different atmospheric conditions. (D) Comparison of modeled to measured $F_{P}$ for all shown acids for four events. Average uncertainty in SIMPOL vapor pressure estimation is approximately \pm 0.4 in $\log \left(v_{P}\right)$, which would shift the 1:1 line to the curved dashed lines. 
A. Model using retention time

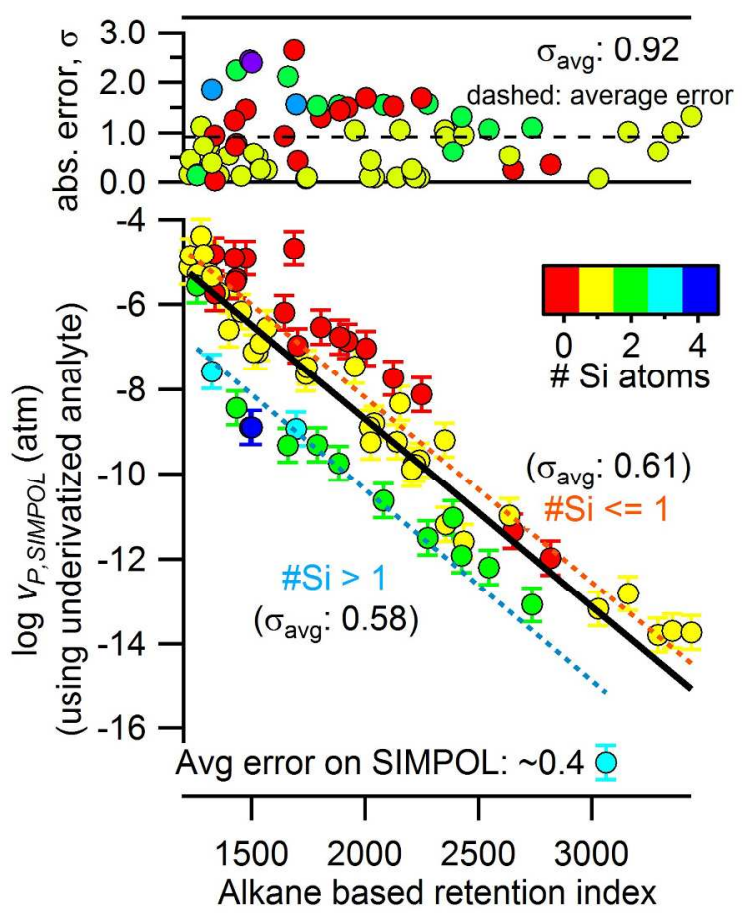

B. Model using retention index and \#Si

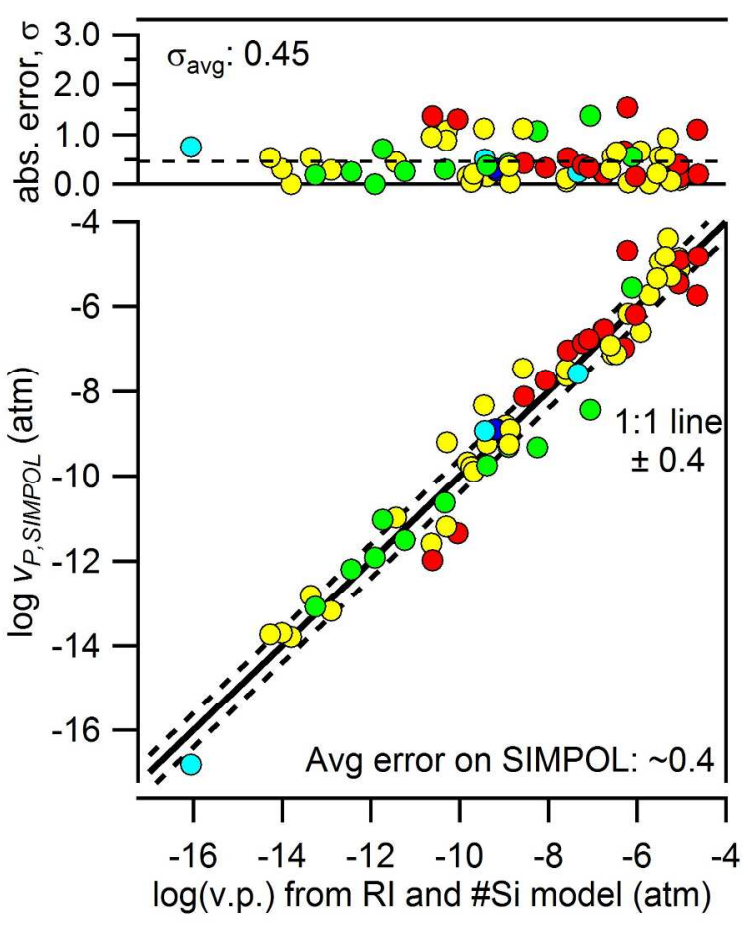

Fig. S5. Correlation between estimated vapor pressure and observed retention time for 68 oxygenated compounds available as authentic standards that have atmospherically relevant functionality. (A) Vapor pressure calculated for the underivatized form of each compound as a function of GC alkane-based retention index, colored by the number of derivatized groups (1 Si atom $=1$ derivatized group). Dashed lines show the fit for compounds containing 0 or 1 derivatized group (orange) or more than 1 (blue). (B) Vapor pressure calculated from SIMPOL compared to that modeled using a two-variable regression fit of retention index (RI) and number. Top panel shows the absolute residual of the fit in each case. 


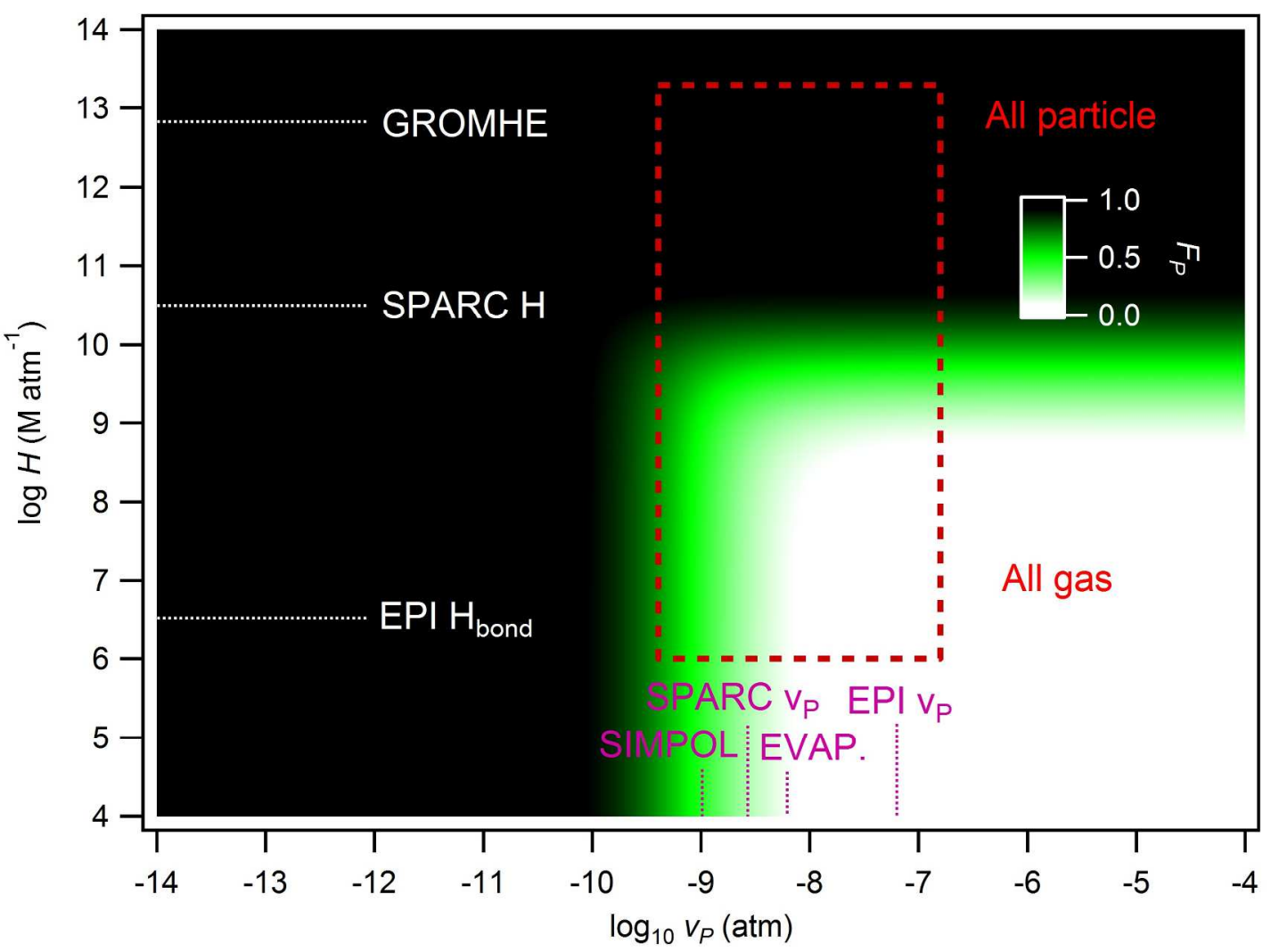

Fig. S6. Parameter space to predict $F_{P}$ for a particle with a composition similar to the median particle observed at SOAS (liquid water: $7.7 \mu \mathrm{g} \mathrm{m}^{-3}$, organic mass: $4.5 \mu \mathrm{g} \mathrm{m}^{-3}$ ), assuming two separate liquid phases. Estimated parameters for 2-methylerythritol from common group contribution methods are shown in white (Henry's law constants) and purple (vapor pressure). Region of estimated parameters are shown in red dashed box (including a one half order of magnitude uncertainty for all parameters). 
A. Absorption into organic mass only:

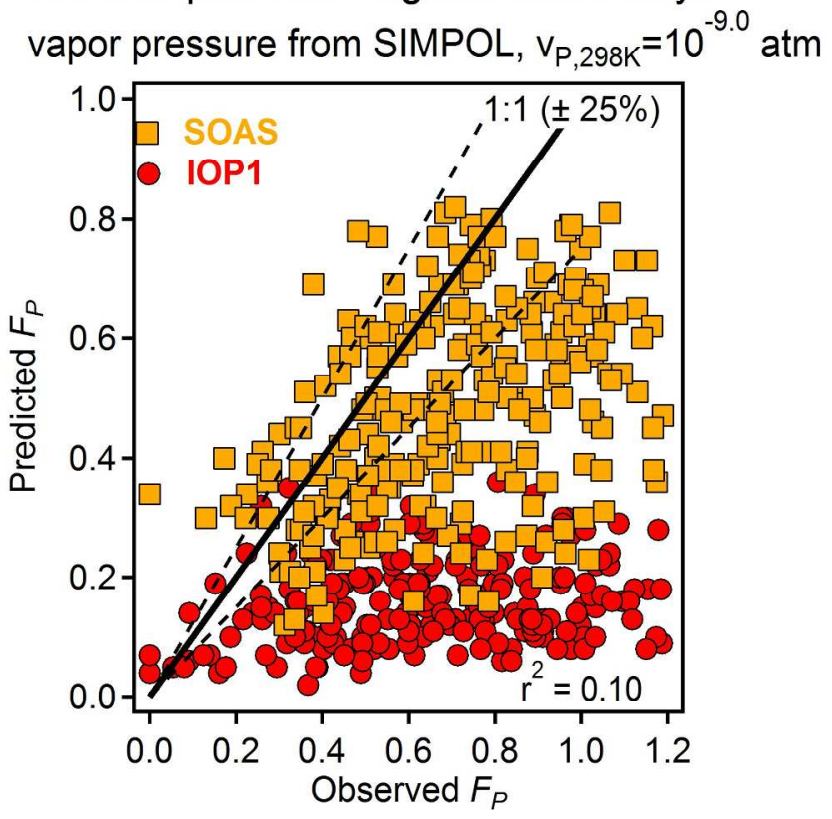

Optimized uptake coeffiecients:

\section{B. Absorption into mixed aqueous-organic phase}

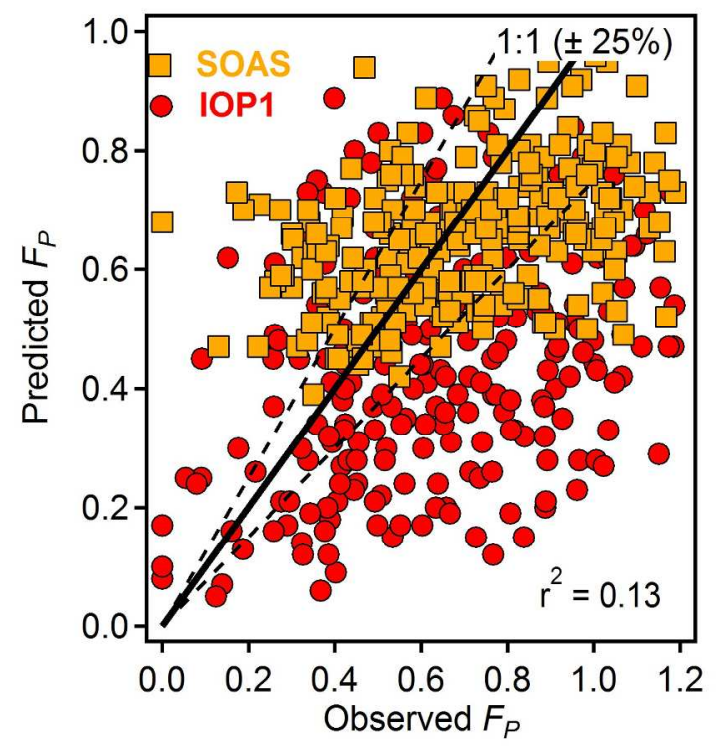

C. Absorption into mixed organic mass only, effective $v_{P, 298 K}=10^{-9.7}$ atm

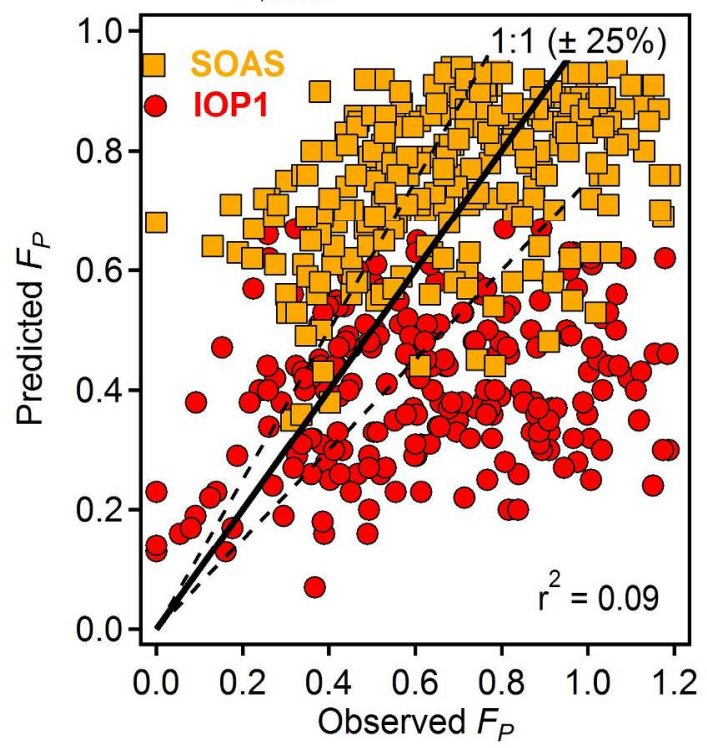

Fig. S7. Particle fraction predicted by absorptive partitioning compared to observed hourly particle fraction for 2-methylerythritol assuming absorption into (A) organic mass based on the vapor pressure estimated by SIMPOL, or and with optimized uptake parameters that minimize average deviation between model and observations assuming absorption into (B) a single organic-rich aqueous phase with an effective Henry's law constant, or (C) organic mass only with an effective saturated concentration/vapor pressure. Includes data from the Amazon wet season (red circles) and the southeastern U.S. (orange squares). Black line is 1:1 line ( $\pm 25 \%$ ) 
802

803

804

805

806

807

808

809

810

811

812

813

814

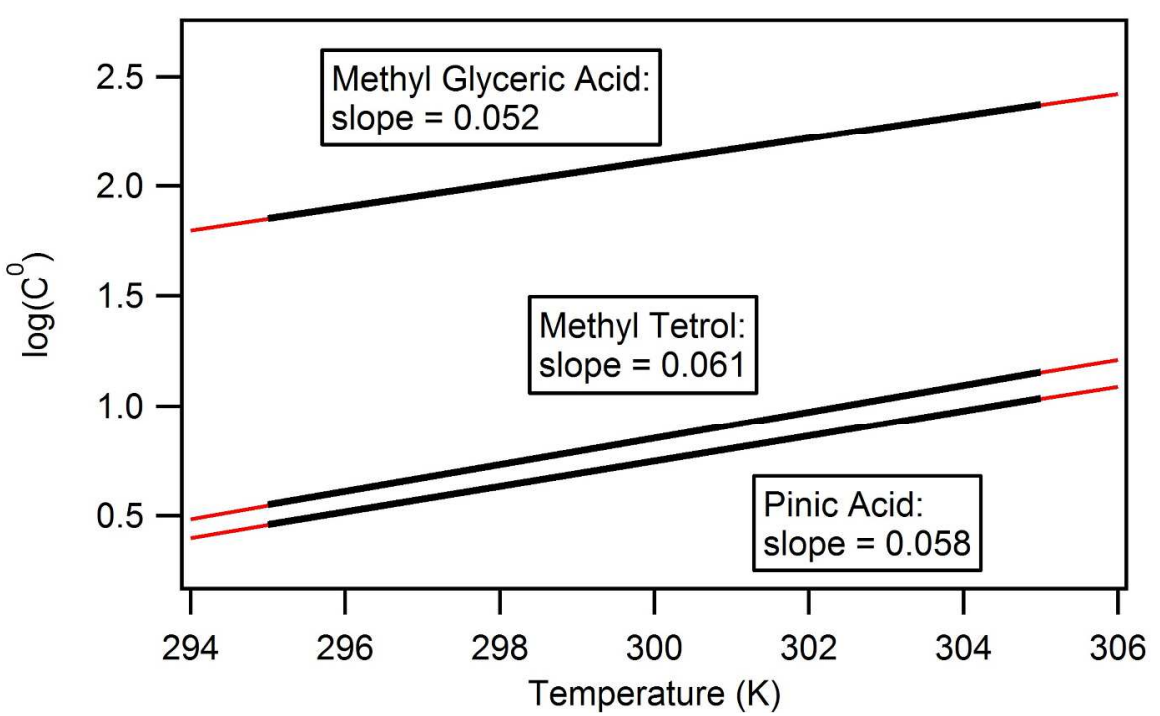

Fig. S8. Log saturation concentration for three common and chemically different BVOC oxidation products in the ambient temperature range as calculated from SIMPOL. Linear fits between 295 and $305 \mathrm{~K}$ are shown in black.
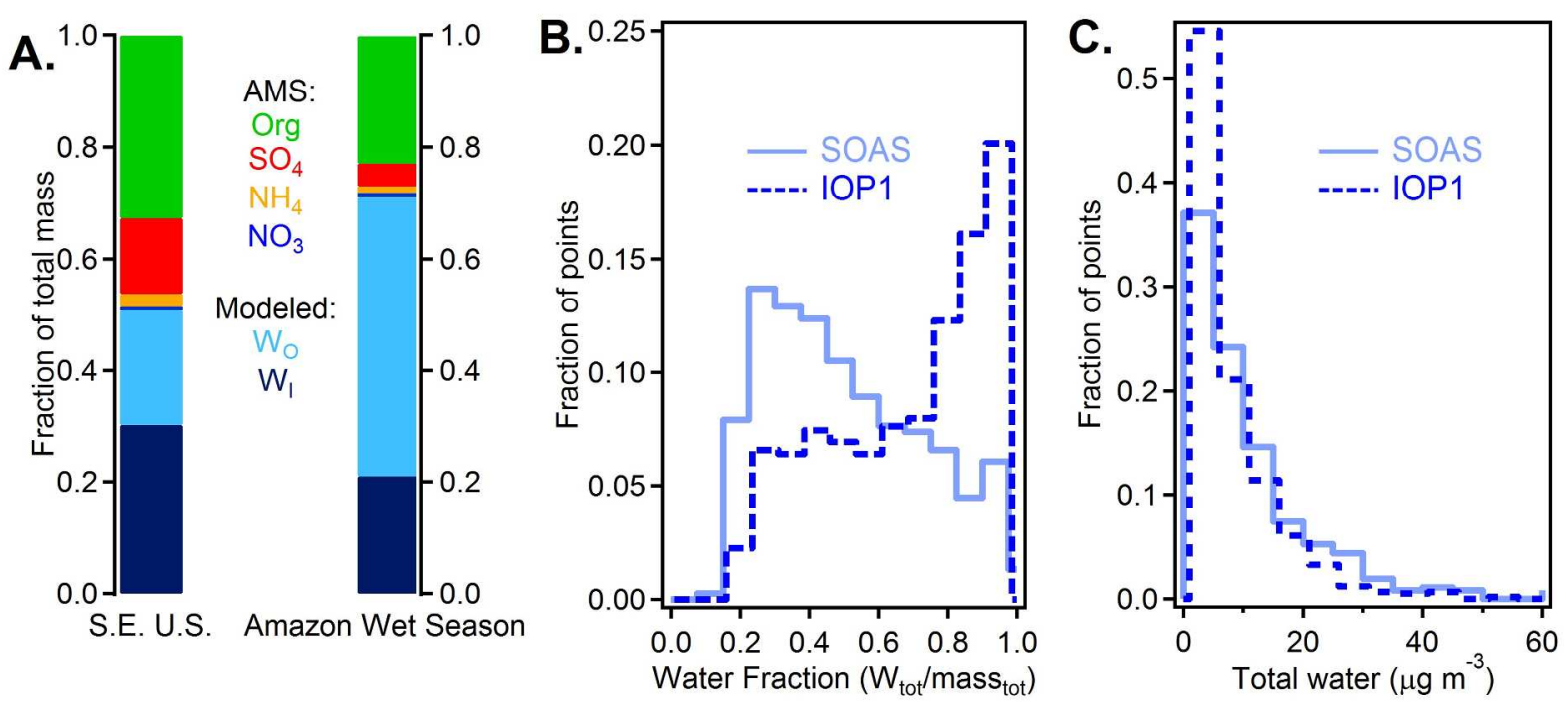

Fig. S9. Particle-phase composition at both sites, including (A) campaign-long average mass fractions of each component. Histograms of the quantity of total - including inorganic and organic - particle-phase liquid water content shown as (B) total mass fraction and (C) total concentration at both sites (light solid: S.E. U.S; dark dashed: Amazon wet season). 
815

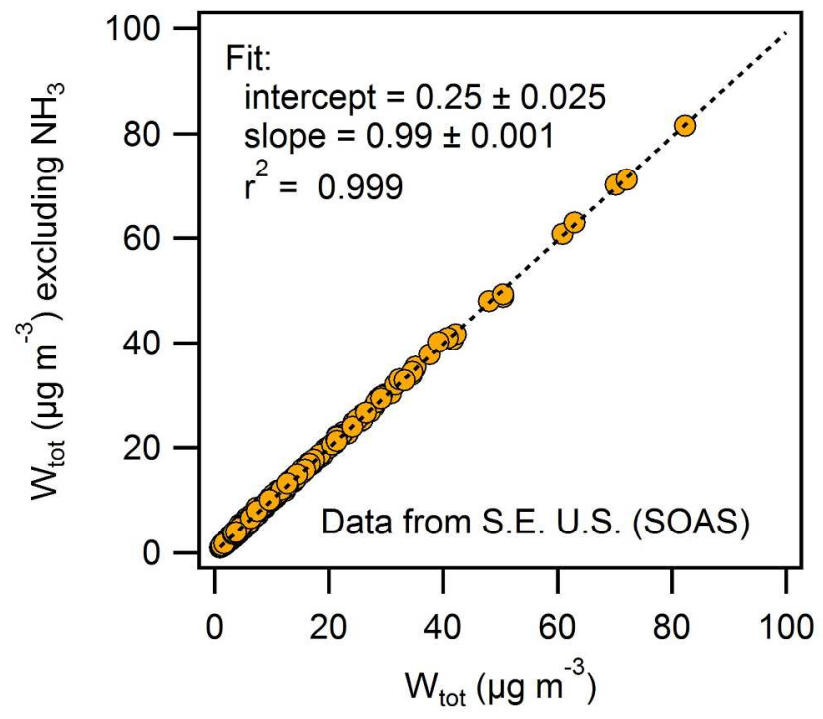

817 Fig. S10. Comparison of calculated total water with and without the inclusion of gas-phase $\mathrm{NH}_{3}$ 818 measurements during SOAS. 


\section{SOAS}
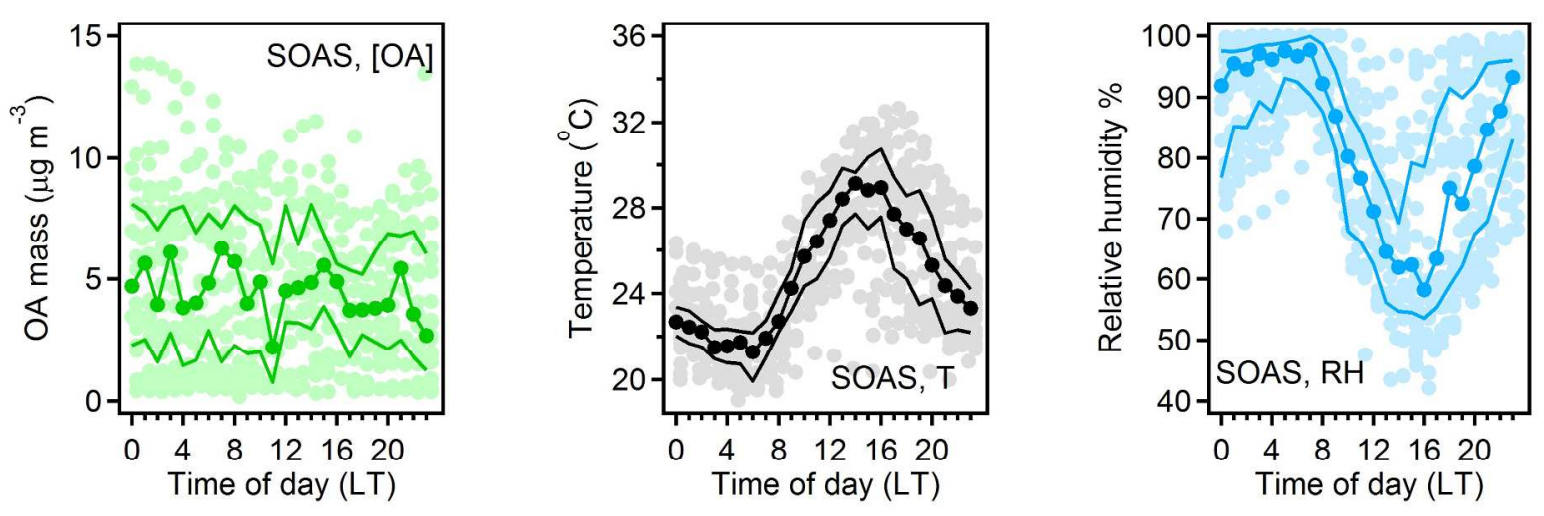

GoAmazon IOP1

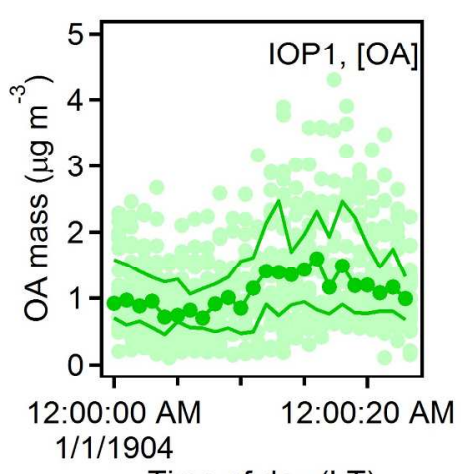

Time of day (LT)
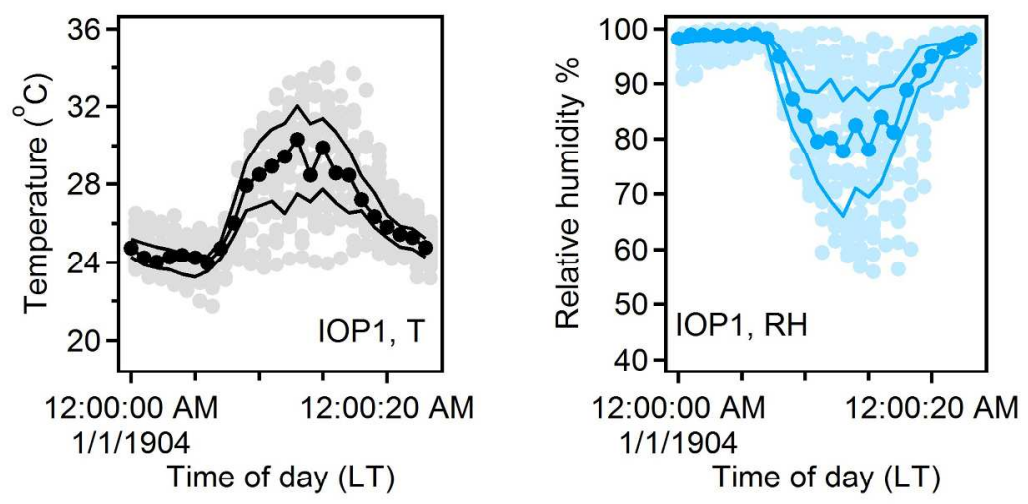

GoAmazon IOP2
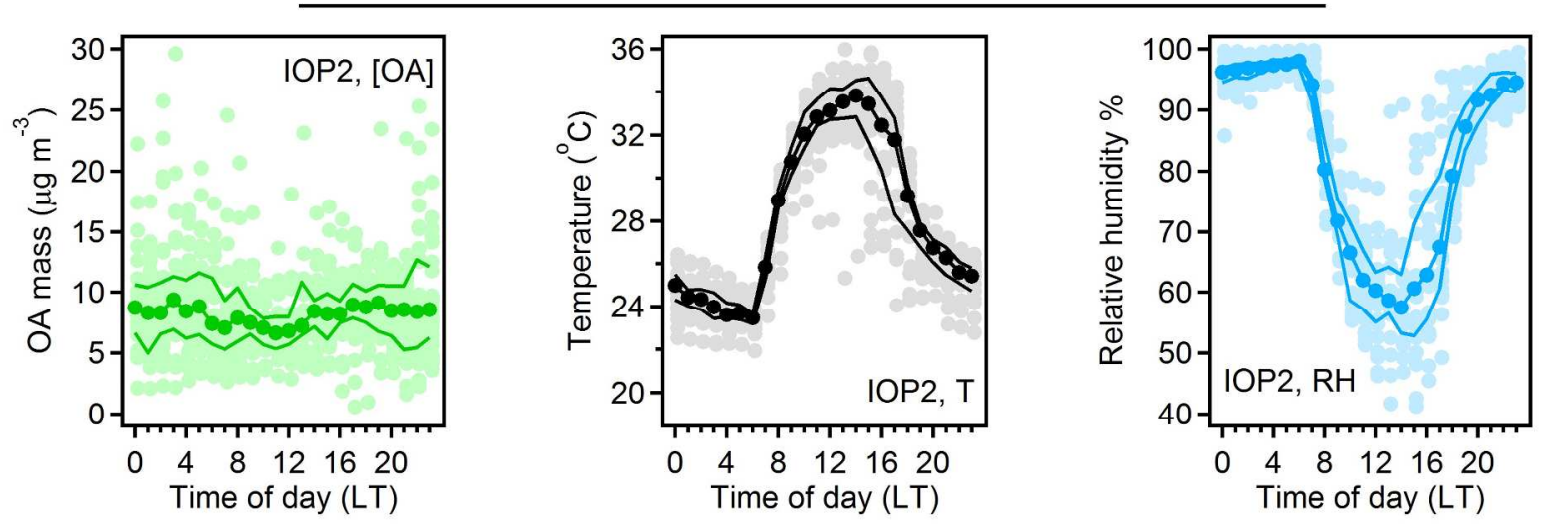

Fig. S11. Diurnal profiles of measured organic aerosol mass (left), temperature (middle), and relative humidity (right) during SOAS (top), IOP1 (center), and IOP2 (bottom). Only data for the periods coinciding with reported SV-TAG measurements are shown. 

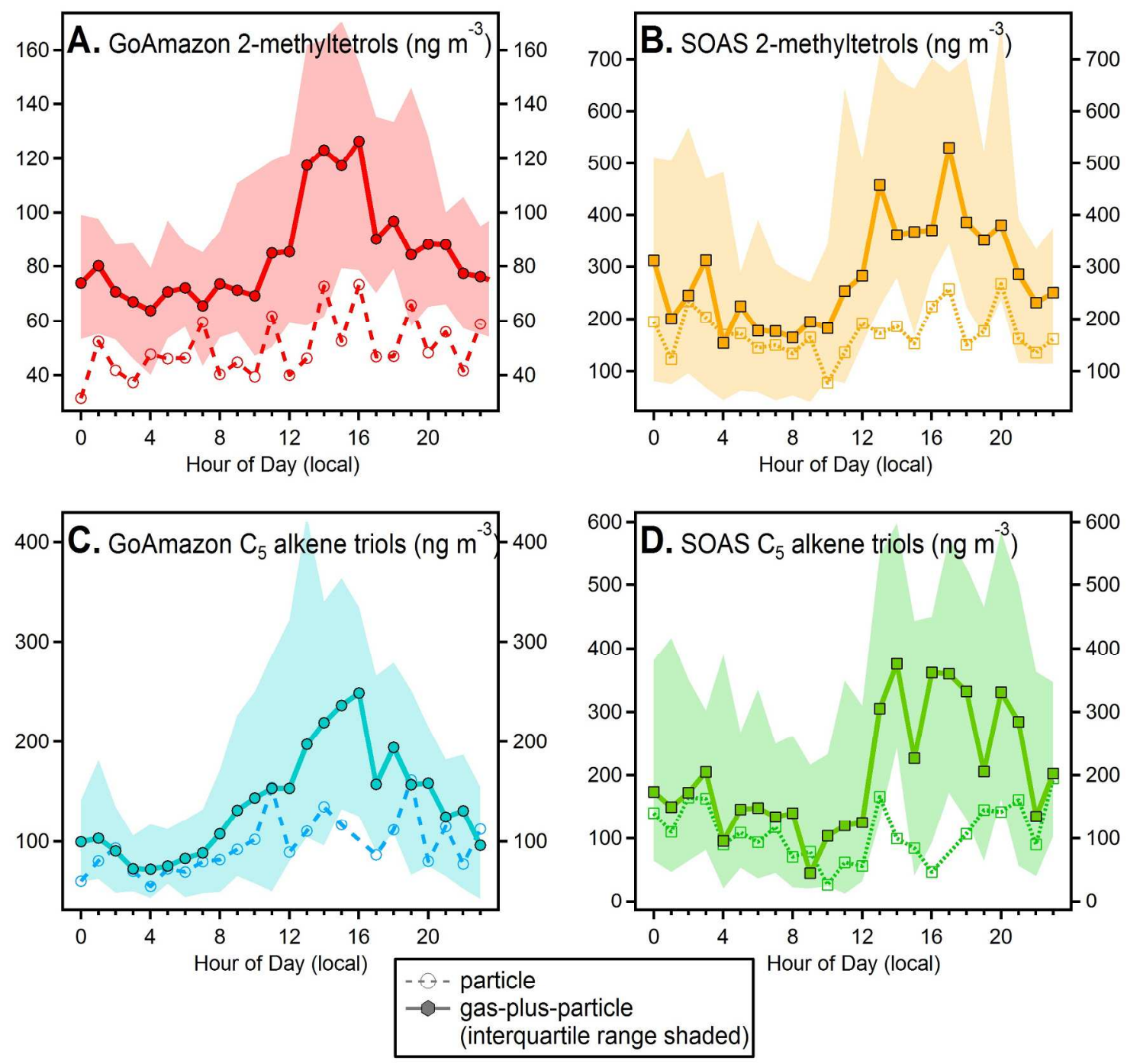

Fig. S12. Diurnal trends in concentrations of 2-methyltetrols and $\mathrm{C}_{5}$ alkene triols during SOAS and GoAmazon IOP1, as labeled. Expanded view of Figs. 1c and d. 


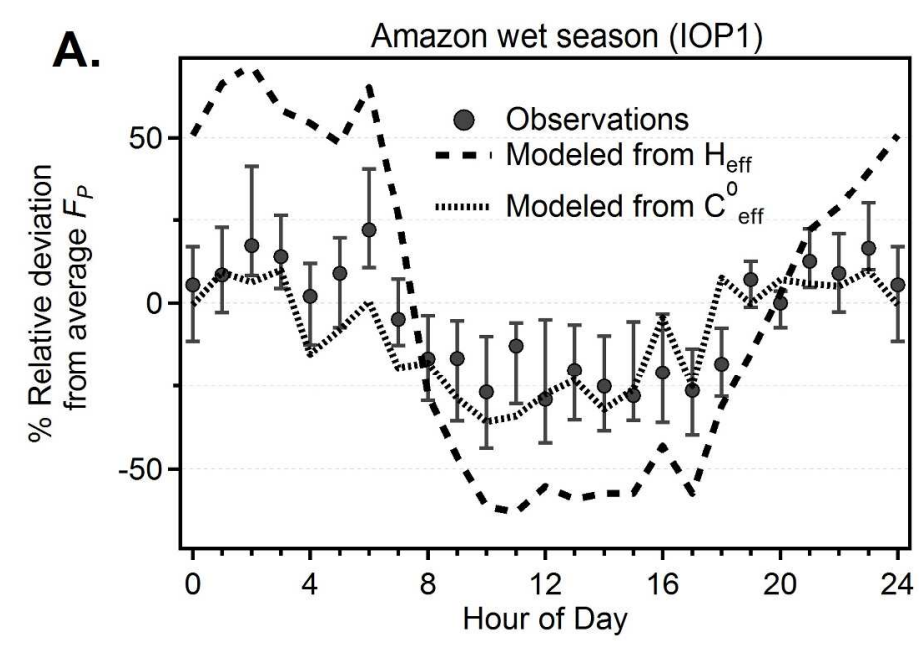

S.E. U.S. (SOAS)

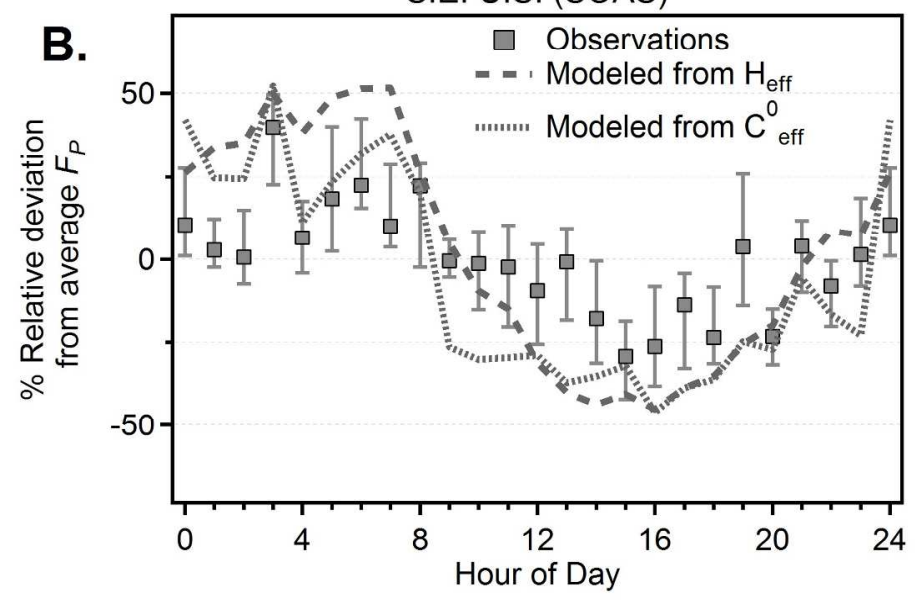

830 Fig. S13. Comparison of observed average diurnal trends in relative $F_{P}$ for all observed 831 compounds (markers) and expected for partitioning based on effective saturation concentration, $832 C_{e f f}^{0}$ (i.e. partitioning into organics only; dotted) and effective Henry's law constant $\left(H_{\text {eff }}\right)$ (i.e. 833 partitioning into combined organics and water; dashed) at (A) GoAmazon2014/5 IOP1 and (B) 834 SOAS. 


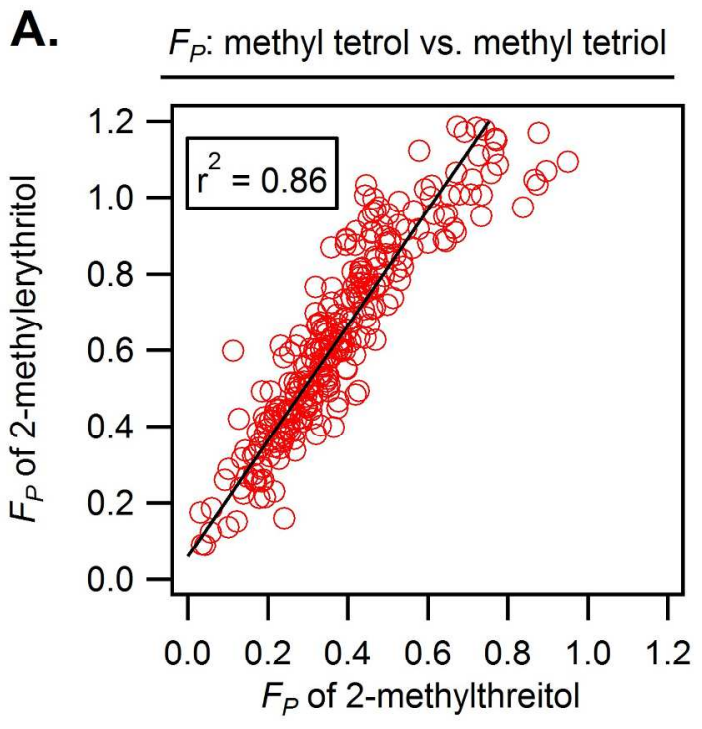

836

837

838

839

840

841

842

843

844 in Fig. 3 in the main text.

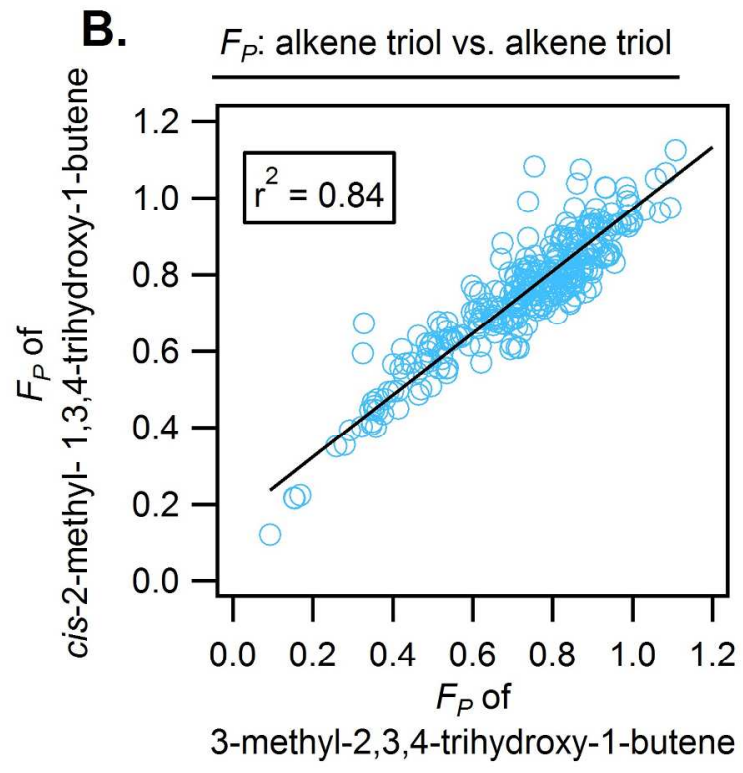

Fig. S14 Comparison of observed fraction in the particle at GoAmazon2014/5 IOP1 of (A) two methyl tetrol isomers and (B) two $\mathrm{C}_{5}$ alkene triol isomers.

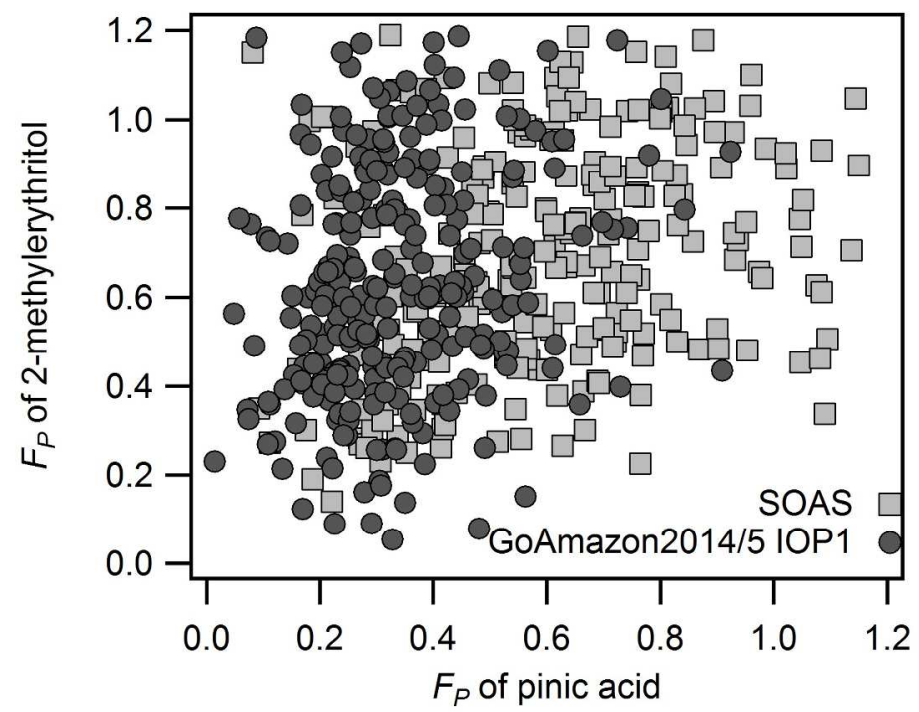

Fig. S15. Observed fraction in the particle at GoAmazon2014/5 IOP1 (circles) and SOAS (squares) of 2-methylerythritol against pinic acid. Equivalent to a comparison of the bottom axes 


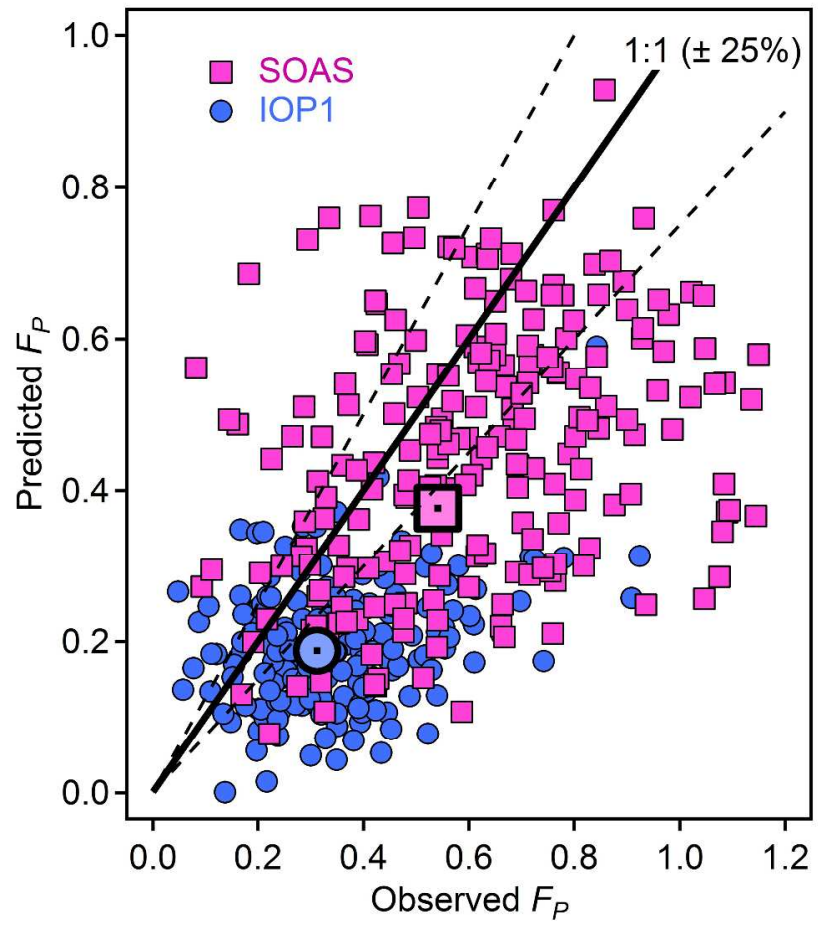

Fig. S16. Particle fraction predicted by equilibrium absorptive partitioning into an organic mass based on vapor pressure compared to observed hourly particle fraction for pinic acid. Includes data from the Amazon wet season (purple circles) and the southeastern U.S. (pink squares), with campaign averages as large outlined markers. Black line is 1:1 line $( \pm 25 \%)$ 


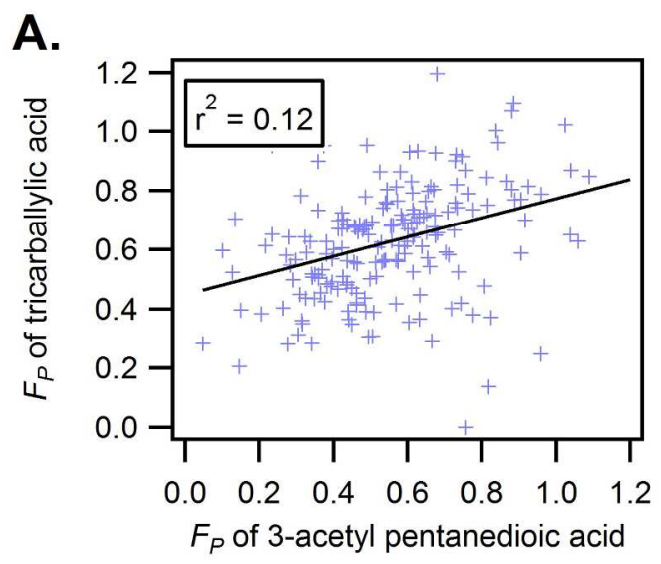

C.

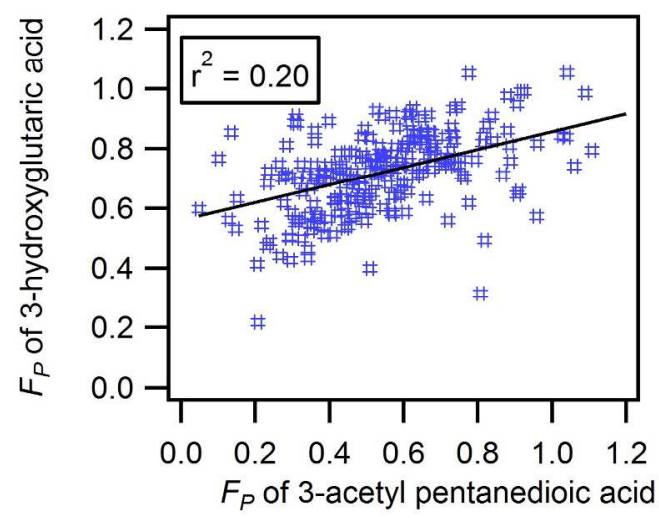

E.

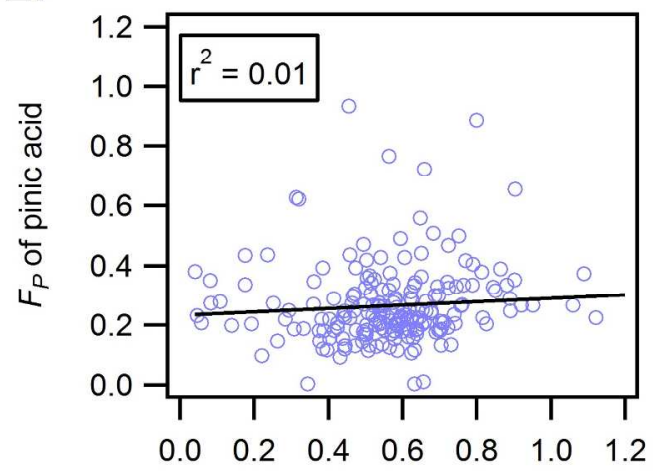

$F_{P}$ of 3-methyl-1,2,3-butane tricarboxylic acid
B.

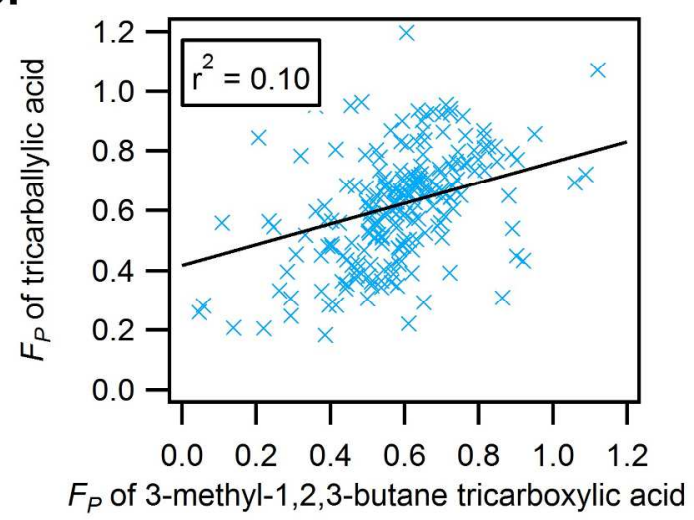

D.

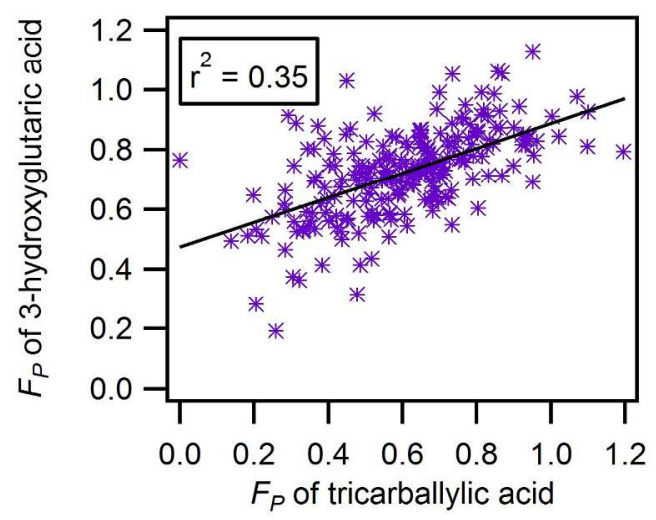

F.

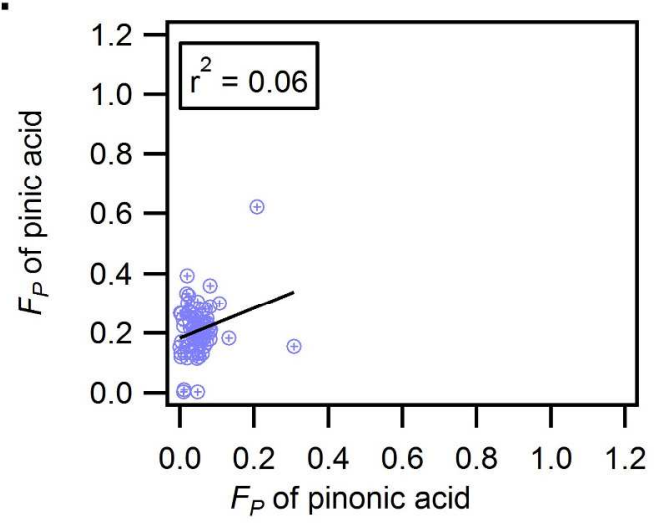

Fig. S17. Comparison of observed $F_{P}$ at GoAmazon2014/5 IOP1 of several $\alpha$-pinene oxidation products including (A) tricarballylic acid vs. 3-acetyl pentanedioic acid, (B) tricarballylic acid vs. 3-methyl-1,2,3-butane tricarboxylic acid (MBTCA), (C) 3-hydroxyglutaric acid vs. 3-acetyl pentanedioic acid, (D) 3-hydroxyglutaric acid vs. tricarballylic acid, (E) pinic acid vs MBTCA, and (F) pinic acid vs. pinonic acid. Linear fit and correlation coefficient is shown in each case. 


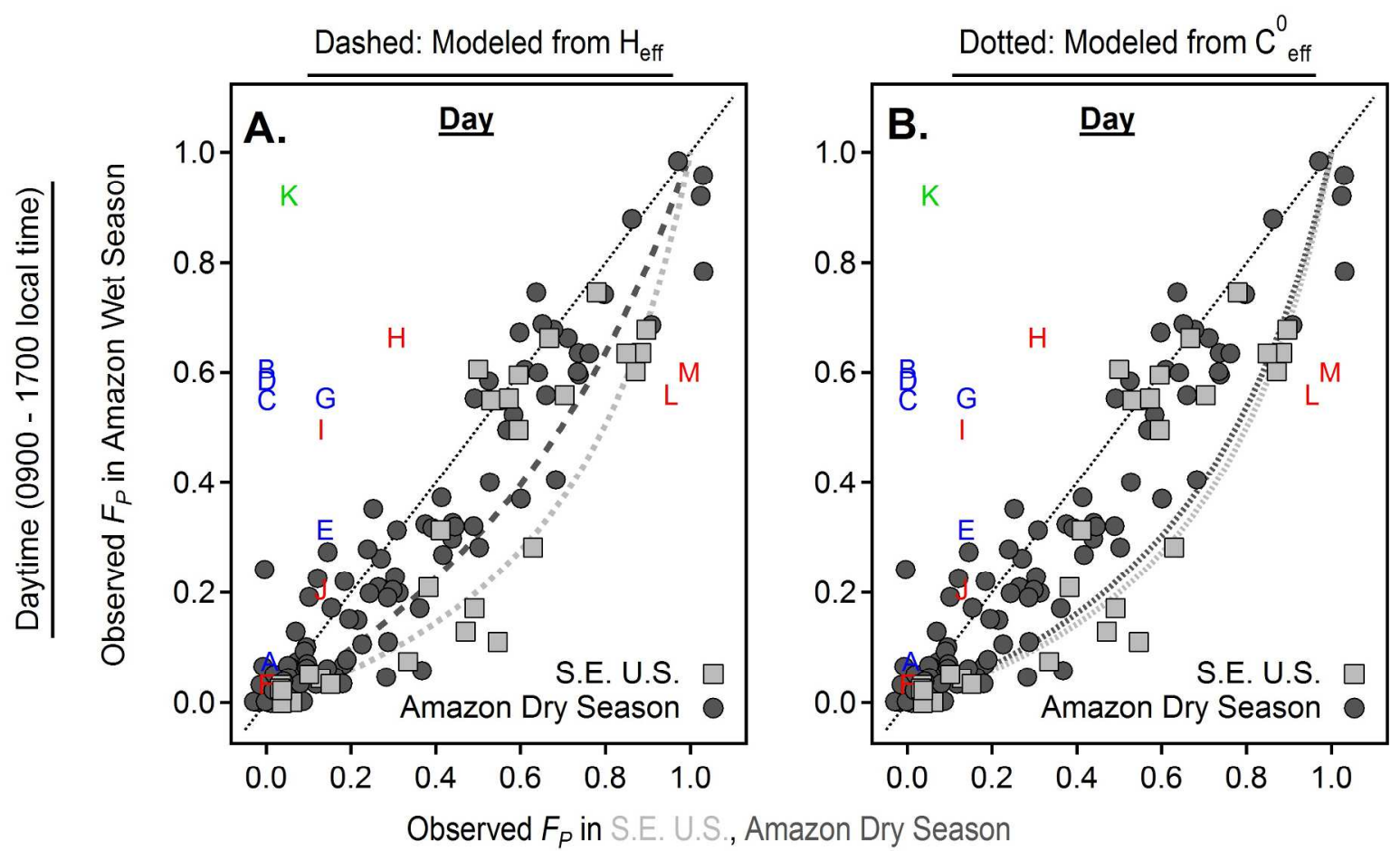

Letters modeled from $v_{p}$

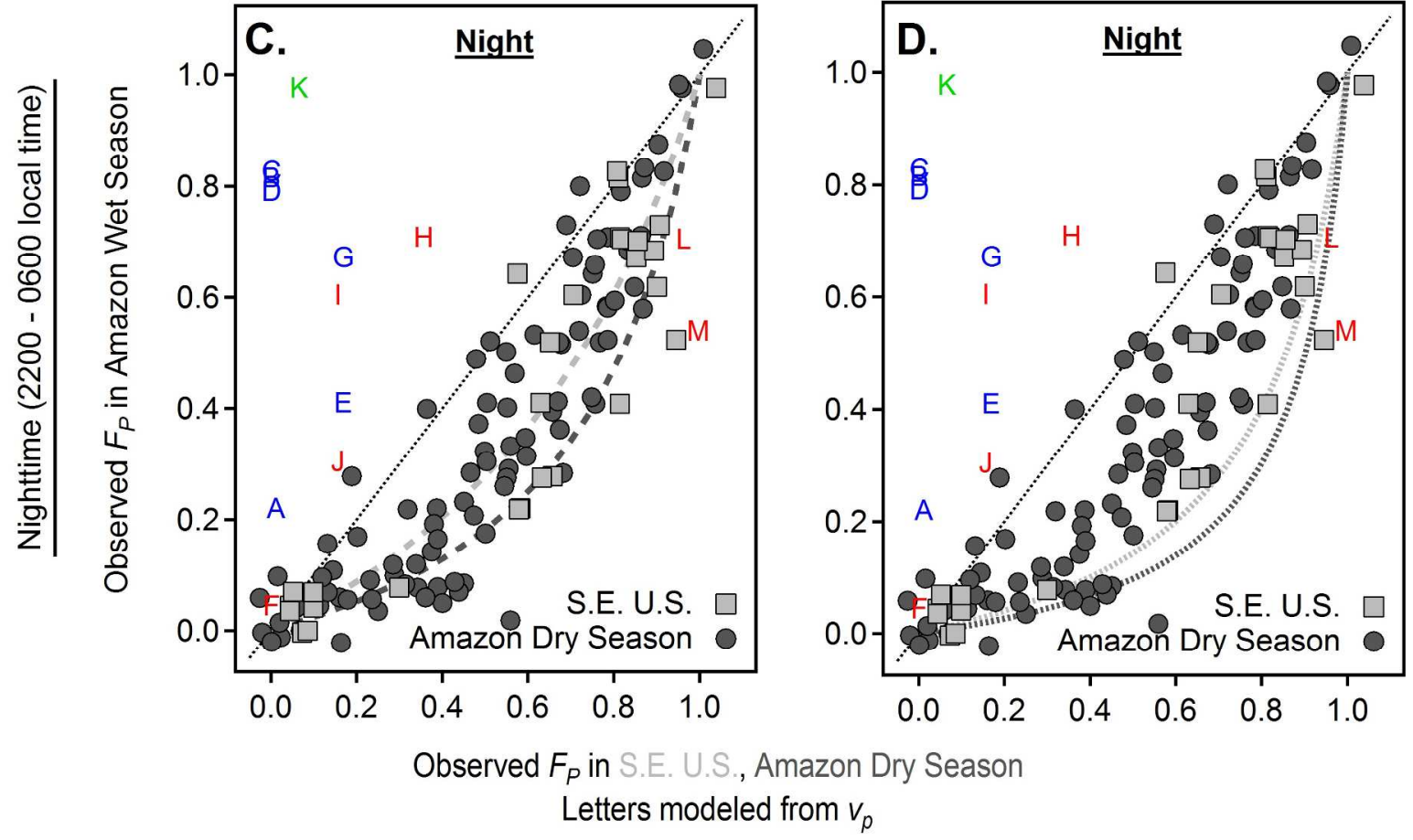

Fig. S18. Comparison of observed $F_{P}$ between field campaigns (as in Figure $4 \mathrm{~b}$ ) split into (A,B) day and $(\mathbf{C , D})$ night. Predicted $F_{P}$ at each campaign calculated based on differences in particle 861 composition from IOP1 is shown based on (left panels) effective Henry's law constant (dashed 862 line) and (right panels) effective saturation concentration (dotted line). 

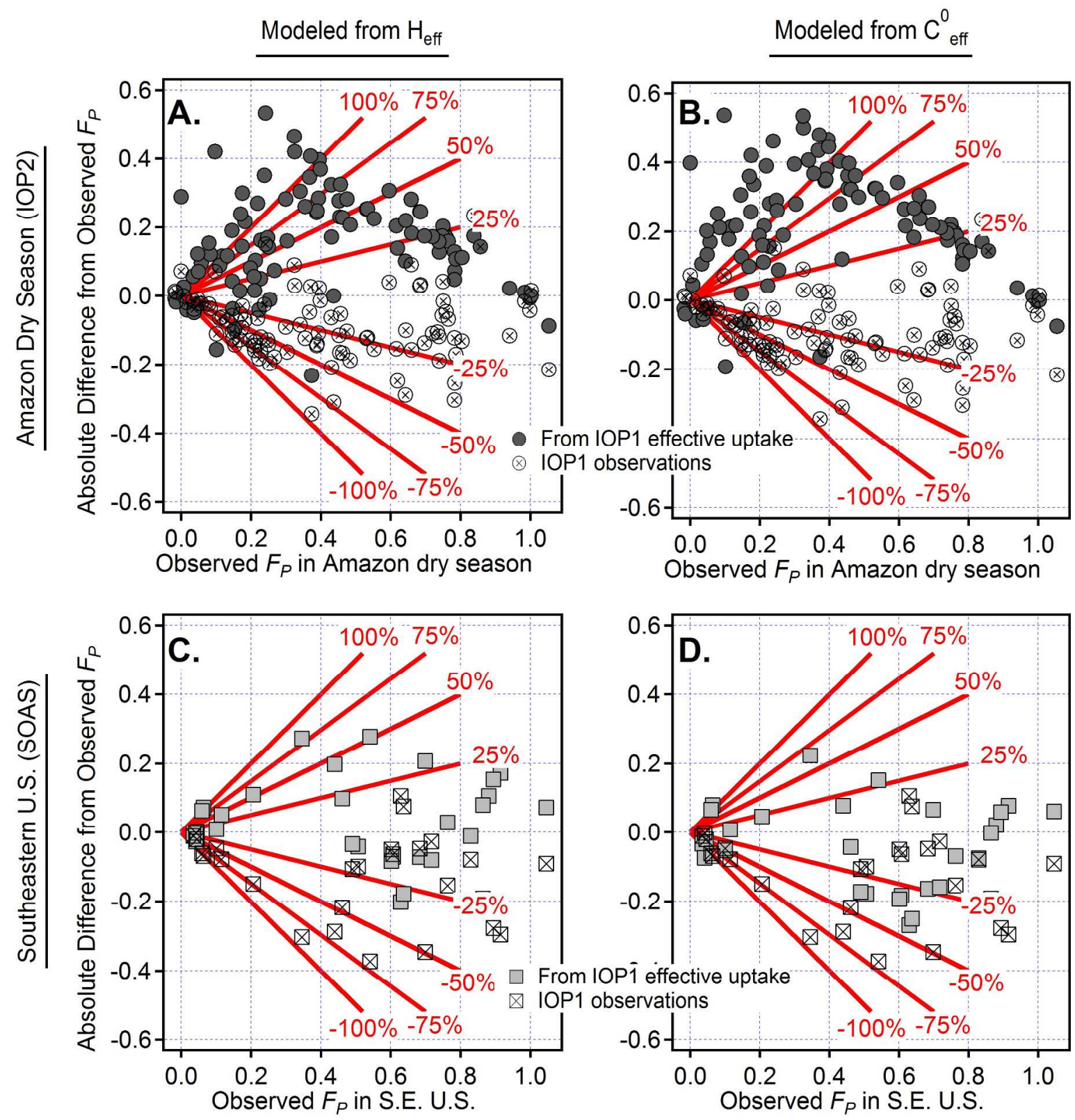

864

865

866

867

868

869

870

871

Fig. S19. Difference of observed $F_{P}$ at each campaign from GoAmazon2014/5 IOP1 observations (crossed markers) and from that estimated from differences in temperature, organic mass, and particle phase liquid water (solid markers) for each campaign. Differences are shown for IOP2 based on (A) $H_{\text {eff }}$ and (B) $C_{e f f}^{0}$ and for SOAS based on (C) $H_{\text {eff }}$ and (D) $C_{e f f}^{0}$. Points are shown in absolute terms, and red lines represent slopes of relative error. 
Table S1. Difference between observed and modeled $F_{P}$ for 2-methylerythritol partitioning into particles that contain two separate liquid phases ${ }^{24}$ using Henry's law constants and vapor pressures calculated through various group contribution methods. Average relative difference between model and observations $\left(\frac{F_{P, m o d}-F_{P, o b s}}{F_{P, o b s}}\right)$ is shown in percent, with $\mathrm{r}^{2}$ of regression in parentheses.

\begin{tabular}{|c|c|c|c|c|c|c|}
\hline & & & \multicolumn{4}{|c|}{$\log v_{p}(a t m)$} \\
\hline & & & $S I M P O L^{a}$ & $S P A R C v_{P}^{b}$ & $E^{\prime} A P^{c}$ & $E P I v_{P}^{d}$ \\
\hline & & & -9.0 & -8.6 & -8.2 & -7.2 \\
\hline \multirow{3}{*}{ 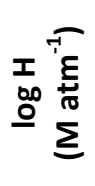 } & $G R O M H E^{e}$ & 12.8 & $81 \%(0.05)$ & $81 \%(0.05)$ & $81 \%(0.05)$ & $81 \%(0.05)$ \\
\hline & $S P A R C H^{b}$ & 10.5 & $35 \%(0.14)$ & $32 \%(0.14)$ & $30 \%(0.14)$ & $30 \%(0.14)$ \\
\hline & EPI $\mathrm{H}_{\text {bond }}{ }^{d}$ & 6.5 & $-47 \%(0.11)$ & $-71 \%(0.11)$ & $-86 \%(0.10)$ & $-98 \%(0.10)$ \\
\hline
\end{tabular}

${ }^{a}$ Pankow and Asher ${ }^{21}{ }^{b}$ Hilal et al. ${ }^{25}{ }^{\mathrm{c}}$ EVAPORATION, Compernolle et al. ${ }^{26}{ }^{\mathrm{d}}$ Bond contribution of the HENRYWIN module of the EPI suite ${ }^{27}$ is used here (EPI $\mathrm{H}_{\text {bond }}$ ), as it is preferred in this case over the group contribution method and previous work as found it to be more accurate. ${ }^{\mathrm{e}}$ Raventos-Duran et al. ${ }^{28}$

Table S2. Difference between observed and modeled $F_{P}$ for 2-methylerythritol partitioning into particles that contain a single aqueous phases with an effective Henry's law constants calculated by SPARC for various solvents. Average relative difference between model and observations $\left(\frac{F_{P, \text { mod }}-F_{P, o b s}}{F_{P, o b s}}\right)$ is shown, with $\mathrm{r}^{2}$ of regression in parentheses.

\begin{tabular}{|c|c|c|}
\hline Single-phase solvent & $\begin{array}{c}\log \mathrm{H} \\
\left(\mathrm{M} \mathrm{atm}^{-1}\right)\end{array}$ & Model bias $\left(r^{2}\right)$ \\
\hline $50 \%$ water, $^{50 \%}$ organic $^{a}$ & 9.6 & $-24 \%(0.13)$ \\
\hline $100 \%$ methoxyethanol & 8.5 & $-85 \%(0.09)$ \\
\hline $50 \%$ water, $50 \%$ methoxyethanol & 10.1 & $21 \%(0.14)$ \\
\hline model optimization $^{\mathrm{b}}$ & 9.8 & $0 \%(0.13)$ \\
\hline
\end{tabular}

a Organic refers to "generic organic" (XGENORG) in SPARC calculator

${ }^{\mathrm{b}}$ Estimated $H$ adjusted to minimize model error 
Table S3. Functionality and uptake parameters for a-pinene oxidation products shown in Fig. S15, including, from left to right, Henry's law constant estimated using SPARC, molecular formula, number of hydroxyl groups, number of carbonyl groups, and number of carboxylic acid groups

\begin{tabular}{|l|c|c|c|c|c|}
\hline \multicolumn{1}{|c|}{$\alpha$-pinene oxidation product } & $\begin{array}{c}\text { log } \mathrm{H} \\
\left(\mathrm{M} \mathrm{atm}^{-1}\right)\end{array}$ & Formula & \#OH & \#C=O & \#COOH \\
\hline 3-acetyl pentanedioic acid & 11.66 & $\mathrm{C} 7 \mathrm{H} 1005$ & 0 & 1 & 2 \\
tricarballylic acid & 11.28 & $\mathrm{C} 6 \mathrm{H} 8 \mathrm{O} 6$ & 0 & 0 & 3 \\
3-hydroxy glutaric acid & 10.83 & $\mathrm{C} 5 \mathrm{H} 805$ & 1 & 0 & 2 \\
3-methyl-1,2,3-butanetricarboxylic acid (MBTCA) & 10.28 & $\mathrm{C} 8 \mathrm{H} 12 \mathrm{O} 6$ & 0 & 0 & 3 \\
pinic acid & 9.01 & $\mathrm{C} 9 \mathrm{H} 1404$ & 0 & 0 & 2 \\
pinonic acid & 6.78 & $\mathrm{C} 10 \mathrm{H} 16 \mathrm{O} 3$ & 0 & 1 & 1 \\
\hline
\end{tabular}

Table S4. Average $F_{P}$ during daytime and nighttime at all three measurement campaigns in this study, and average across all three. Average difference between night and day shown in rightmost column.

\begin{tabular}{|c|c|c|c|c|c|c|c|c|c|c|}
\hline & \multirow[b]{2}{*}{ Name } & \multicolumn{2}{|c|}{ SOAS } & \multicolumn{2}{|c|}{ IOP1 } & \multicolumn{2}{|c|}{ IOP2 } & \multicolumn{3}{|c|}{ Averages } \\
\hline & & Day & Night & Day & Night & Day & Night & Day & Night & $\Delta$ \\
\hline A & 2-methyl glyceric acid & 0.33 & 0.58 & 0.07 & 0.22 & 0.07 & 0.39 & $0.16 \pm 0.12$ & $0.40 \pm 0.15$ & 0.24 \\
\hline B & $\begin{array}{l}\text { cis-2-methyl-1,3,4- } \\
\text { trihydroxy-1-butene }\end{array}$ & 0.50 & 0.81 & 0.60 & 0.82 & 0.61 & 0.87 & $0.57 \pm 0.05$ & $0.83 \pm 0.02$ & 0.26 \\
\hline C & $\begin{array}{l}\text { 3-methyl-2,3,4- } \\
\text { trihydroxy-1-butene }\end{array}$ & 0.53 & 0.81 & 0.55 & 0.83 & 0.55 & 0.92 & $0.54 \pm 0.01$ & $0.85 \pm 0.05$ & 0.31 \\
\hline D & $\begin{array}{l}\text { trans-2-methyl-1,3,4- } \\
\text { trihydroxy-1-butene }\end{array}$ & b & b & 0.58 & 0.79 & 0.52 & 0.82 & $0.55 \pm 0.03$ & $0.80 \pm 0.01$ & 0.17 \\
\hline E & 2-methythreitol & 0.41 & 0.63 & 0.31 & 0.41 & 0.31 & 0.50 & $0.34 \pm 0.05$ & $0.51 \pm 0.09$ & 0.17 \\
\hline $\mathbf{F}$ & pinonic acid & 0.04 & 0.04 & 0.03 & 0.04 & 0.01 & 0.11 & $0.03 \pm 0.01$ & $0.07 \pm 0.03$ & 0.04 \\
\hline $\mathbf{G}$ & 2-methyerythritol & 0.57 & 0.85 & 0.55 & 0.67 & 0.49 & 0.70 & $0.54 \pm 0.03$ & $0.74 \pm 0.08$ & 0.20 \\
\hline $\mathbf{H}$ & 3-hydroxy glutaric acid & 0.67 & 0.81 & 0.66 & 0.71 & 0.71 & 0.79 & $0.68 \pm 0.02$ & $0.77 \pm 0.04$ & 0.09 \\
\hline I & $\begin{array}{l}\text { 3-acetyl pentanedioic } \\
\text { acid }^{\text {a }}\end{array}$ & 0.59 & 0.71 & 0.50 & 0.60 & 0.57 & 0.72 & $0.55 \pm 0.04$ & $0.68 \pm 0.05$ & 0.13 \\
\hline J & pinic acid & 0.39 & 0.60 & 0.20 & 0.30 & 0.30 & 0.50 & $0.30 \pm 0.08$ & $0.47 \pm 0.12$ & 0.17 \\
\hline $\mathbf{K}$ & levogluclosan & 1.02 & 1.05 & 0.92 & 0.98 & 1.02 & 0.96 & $0.99 \pm 0.05$ & $1.00 \pm 0.04$ & -0.03 \\
\hline $\mathbf{L}$ & tricarballylic acid & 0.70 & 0.82 & 0.56 & 0.71 & 0.66 & 0.76 & $0.64 \pm 0.06$ & $0.76 \pm 0.05$ & 0.12 \\
\hline M & $\begin{array}{l}\text { 3-methyl-1,2,3- } \\
\text { butanetricarboxylic } \\
\text { acid (MBTCA) }\end{array}$ & b & b & 0.60 & 0.54 & 0.64 & 0.72 & $0.62 \pm 0.02$ & $0.63 \pm 0.09$ & 0.01 \\
\hline
\end{tabular}

${ }^{a}$ based on mass spectrum identified as 3-acetyl pentanedioic acid by Jaoui et al.

${ }^{\mathrm{b}}$ not observed above detection limit 
912 Table S5. Average measured effective saturation concentration constant, $\log \left(C_{e f f}^{0}\right)$, during 913 daytime and nighttime at all three measurement campaigns in this study, and average across all 914 three. Average difference between night and day shown in rightmost column.

\begin{tabular}{|c|c|c|c|c|c|c|c|c|c|c|}
\hline & \multirow[b]{2}{*}{ Name } & \multicolumn{2}{|c|}{ SOAS } & \multicolumn{2}{|c|}{ IOP1 } & \multicolumn{2}{|c|}{ IOP2 } & \multicolumn{3}{|c|}{ Averages } \\
\hline & & Day & Night & Day & Night & Day & Night & Day & Night & $\Delta$ \\
\hline A & 2-methyl glyceric acid & 0.97 & 0.55 & 1.26 & 0.55 & 2.05 & 1.16 & $1.43 \pm 0.46$ & $0.76 \pm 0.29$ & -0.67 \\
\hline B & $\begin{array}{l}\text { cis-2-methyl- 1,3,4- } \\
\text { trihydroxy-1-butene }\end{array}$ & 0.67 & 0.07 & -0.02 & -0.64 & 0.75 & 0.15 & $0.47 \pm 0.35$ & $-0.14 \pm 0.36$ & -0.61 \\
\hline C & $\begin{array}{l}\text { 3-methyl-2,3,4- } \\
\text { trihydroxy-1-butene }\end{array}$ & 0.62 & 0.08 & 0.08 & -0.68 & 0.85 & -0.08 & $0.52 \pm 0.32$ & $-0.23 \pm 0.33$ & 0.74 \\
\hline D & $\begin{array}{l}\text { trans-2-methyl-1,3,4- } \\
\text { trihydroxy-1-butene }\end{array}$ & b & b & 0.01 & -0.58 & 0.90 & 0.32 & $0.46 \pm 0.44$ & $-0.13 \pm 0.45$ & -0.59 \\
\hline $\mathbf{E}$ & 2-methythreitol & 0.83 & 0.47 & 0.50 & 0.16 & 1.30 & 0.96 & $0.88 \pm 0.33$ & $0.53 \pm 0.33$ & -0.35 \\
\hline $\mathbf{F}$ & pinonic acid & 2.11 & 2.04 & 1.64 & 1.33 & 2.94 & 1.86 & $2.23 \pm 0.54$ & $1.74 \pm 0.30$ & -0.49 \\
\hline G & 2-methyerythritol & 0.55 & -0.06 & 0.07 & -0.31 & 0.96 & 0.59 & $0.53 \pm 0.36$ & $0.07 \pm 0.38$ & -0.46 \\
\hline H & 3-hydroxy glutaric acid & 0.37 & 0.06 & -0.13 & -0.39 & 0.55 & 0.40 & $0.26 \pm 0.29$ & $0.02 \pm 0.32$ & -0.24 \\
\hline $\mathbf{I}$ & $\begin{array}{l}\text { 3-acetyl pentanedioic } \\
\text { acid }^{\text {a }}\end{array}$ & 0.51 & 0.32 & 0.17 & -0.18 & 0.83 & 0.55 & $0.50 \pm 0.27$ & $0.23 \pm 0.30$ & -0.27 \\
\hline J & pinic acid & 0.87 & 0.52 & 0.75 & 0.36 & 1.32 & 0.96 & $0.98 \pm 0.24$ & $0.61 \pm 0.25$ & -0.37 \\
\hline K & levogluclosan & c & c & c & c & $\mathrm{c}$ & 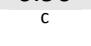 & $\bar{c}$ & c & c \\
\hline $\mathbf{L}$ & tricarballylic acid & 0.30 & 0.04 & 0.06 & -0.38 & 0.66 & 0.46 & $0.34 \pm 0.25$ & $0.04 \pm 0.34$ & -0.30 \\
\hline $\mathbf{M}$ & $\begin{array}{l}\text { 3-methyl-1,2,3- } \\
\text { butanetricarboxylic } \\
\text { acid (MBTCA) }\end{array}$ & $\mathrm{b}$ & $b$ & -0.01 & -0.07 & 0.69 & 0.56 & $0.34 \pm 0.35$ & $0.24 \pm 0.31$ & -0.10 \\
\hline
\end{tabular}

915

916

917

918

919

920

${ }^{a}$ based on mass spectrum identified as 3-acetyl pentanedioic acid by Jaoui et al. ${ }^{7}{ }^{\mathrm{b}}$ not observed above detection limit $\quad{ }^{\mathrm{c}}$ average $F_{P}=1.0$, effective uptake cannot be calculated

Table S6. Average measured effective Henry's laws constant for the ambient mixed particle, $\log \left(H_{\text {mix,eff }}\right)$, during daytime and nighttime at all three measurement campaigns in this study, and average across all three. Average difference between night and day shown in rightmost column.

\begin{tabular}{|c|c|c|c|c|c|c|c|c|c|c|}
\hline & \multirow[b]{2}{*}{ Name } & \multicolumn{2}{|c|}{ SOAS } & \multicolumn{2}{|c|}{ IOP1 } & \multicolumn{2}{|c|}{ IOP2 } & \multicolumn{3}{|c|}{ Averages } \\
\hline & & Day & Night & Day & Night & Day & Night & Day & Night & $\Delta$ \\
\hline A & 2-methyl glyceric acid & 9.3 & 9.3 & 9.0 & 8.9 & 8.4 & 8.5 & $8.93 \pm 0.38$ & $8.91 \pm 0.32$ & -0.02 \\
\hline B & $\begin{array}{l}\text { cis-2-methyl- 1,3,4- } \\
\text { trihydroxy-1-butene }\end{array}$ & 9.6 & 9.8 & 10.3 & 10.1 & 9.7 & 9.5 & $9.89 \pm 0.30$ & $9.81 \pm 0.22$ & -0.08 \\
\hline C & $\begin{array}{l}\text { 3-methyl-2,3,4- } \\
\text { trihydroxy-1-butene }\end{array}$ & 9.7 & 9.8 & 10.2 & 10.1 & 9.6 & 9.8 & $9.85 \pm 0.26$ & $9.90 \pm 0.16$ & 0.05 \\
\hline D & $\begin{array}{l}\text { trans-2-methyl-1,3,4- } \\
\text { trihydroxy-1-butene }\end{array}$ & b & b & 10.3 & 10.0 & 9.6 & 9.4 & $9.93 \pm 0.35$ & $9.70 \pm 0.32$ & -0.15 \\
\hline E & 2-methythreitol & 9.5 & 9.4 & 9.8 & 9.3 & 9.2 & 8.7 & $9.49 \pm 0.25$ & $9.14 \pm 0.29$ & -0.34 \\
\hline $\mathbf{F}$ & pinonic acid & 8.2 & 7.8 & 8.7 & 8.1 & 7.5 & 7.8 & $8.13 \pm 0.46$ & $7.93 \pm 0.13$ & -0.21 \\
\hline G & 2-methyerythritol & 9.8 & 9.9 & 10.2 & 9.8 & 9.5 & 9.1 & $9.84 \pm 0.29$ & $9.60 \pm 0.35$ & -0.24 \\
\hline $\mathbf{H}$ & 3-hydroxy glutaric acid & 9.9 & 9.8 & 10.4 & 9.8 & 9.9 & 9.3 & $10.10 \pm 0.23$ & $9.65 \pm 0.25$ & -0.45 \\
\hline I & $\begin{array}{l}\text { 3-acetyl pentanedioic } \\
\text { acid }^{\text {a }}\end{array}$ & 9.8 & 9.6 & 10.1 & 9.6 & 9.7 & 9.2 & $9.86 \pm 0.19$ & $9.44 \pm 0.21$ & -0.42 \\
\hline J & pinic acid & 9.4 & 9.4 & 9.5 & 9.1 & 9.2 & 8.7 & $9.38 \pm 0.16$ & $9.06 \pm 0.25$ & -0.33 \\
\hline $\mathbf{K}$ & levogluclosan & r & & & & $r$ & $f$ & r & r & r \\
\hline $\mathbf{L}$ & tricarballylic acid & 10.0 & 9.8 & 10.2 & 9.8 & 9.8 & 9.2 & $10.02 \pm 0.17$ & $9.63 \pm 0.28$ & -0.39 \\
\hline M & $\begin{array}{l}\text { 3-methyl-1,2,3- } \\
\text { butanetricarboxylic } \\
\text { acid (MBTCA) }\end{array}$ & $\mathrm{b}$ & $\mathrm{b}$ & 10.3 & 9.5 & 9.8 & 9.1 & $10.04 \pm 0.26$ & $9.33 \pm 0.18$ & -0.48 \\
\hline
\end{tabular}


Table S7. Compounds shown in Fig. 4 sorted by retention index. Known compounds are labeled with a letter and identified below. The correlation coefficient $\mathrm{R}$ is shown for the best correlation (highest R) within each category of known compound (isoprene products, pinene products, and levoglucosan), with the highest of these three values (bold) determining their categorization and color coding in Fig. 4a. When no correlation greater than 0.6 is found with any known compound, no category is assigned or shown in bold. Retention times and integration ions are provided to facilitate comparison and identification in future studies.

\begin{tabular}{|c|c|c|c|c|c|c|}
\hline $\begin{array}{l}\text { Known compound } \\
\text { letter and name }\end{array}$ & $\begin{array}{l}\text { Retentio } \\
n \text { index }\end{array}$ & $\begin{array}{c}\text { Integratio } \\
n \mathrm{~m} / \mathrm{z}\end{array}$ & $\begin{array}{c}\text { Isoprene } \\
\text { correlatio } \\
n\end{array}$ & $\begin{array}{c}\text { Pinene } \\
\text { correlatio } \\
n\end{array}$ & $\begin{array}{l}\text { Levoglucosa } \\
n \text { correlation }\end{array}$ & $\begin{array}{c}\text { Averag } \\
\text { e } F_{P} \\
\text { (IOP1) }\end{array}$ \\
\hline & 1243 & 129 & 0.74 & 0.60 & 0.09 & 0.29 \\
\hline & 1247 & 129 & 0.79 & 0.65 & 0.06 & 0.35 \\
\hline & 1248 & 231 & 0.58 & 0.62 & 0.07 & 0.41 \\
\hline & 1256 & 228 & 0.92 & 0.82 & -0.09 & 0.25 \\
\hline & 1270 & 205 & 0.17 & 0.25 & -0.12 & 0.05 \\
\hline & 1272 & 144 & 0.86 & 0.75 & 0.01 & 0.42 \\
\hline & 1284 & 231 & 0.92 & 0.86 & 0.00 & 0.32 \\
\hline & 1286 & 159 & 0.76 & 0.73 & -0.02 & 0.03 \\
\hline & 1288 & 170 & 0.61 & 0.71 & -0.02 & 0.08 \\
\hline & 1295 & 143 & 0.65 & 0.66 & 0.03 & 0.21 \\
\hline & 1298 & 217 & 0.85 & 0.80 & -0.06 & 0.39 \\
\hline & 1305 & 117 & 0.81 & 0.77 & -0.01 & $<0.03$ \\
\hline & 1308 & 247 & 0.88 & 0.85 & 0.02 & 0.34 \\
\hline \multirow[t]{4}{*}{ A : 2-methyl glyceric acid } & 1312 & 219 & $n / a^{b}$ & 0.88 & -0.11 & 0.15 \\
\hline & 1321 & 292 & 0.86 & 0.81 & -0.04 & 0.35 \\
\hline & 1333 & 143 & 0.85 & 0.93 & -0.10 & $<0.03$ \\
\hline & 1342 & 245 & 0.82 & 0.86 & 0.01 & 0.50 \\
\hline \multirow{4}{*}{$\begin{array}{l}\text { B : cis-2-methyl- 1,3,4- } \\
\text { trihydroxy-1-butene }\end{array}$} & 1352 & 231 & $n / a^{b}$ & 0.74 & 0.08 & 0.73 \\
\hline & 1354 & 117 & 0.38 & 0.51 & -0.08 & 0.07 \\
\hline & 1364 & 129 & 0.77 & 0.67 & -0.06 & 0.17 \\
\hline & 1370 & 116 & 0.85 & 0.78 & -0.05 & 0.30 \\
\hline $\begin{array}{l}\text { C: 3-methyl-2,3,4- } \\
\text { trihydroxy-1-butene }\end{array}$ & 1377 & 231 & $n / a^{b}$ & 0.72 & 0.07 & 0.71 \\
\hline \multirow{8}{*}{$\begin{array}{l}\text { D : trans-2-methyl- 1,3,4- } \\
\text { trihydroxy-1-butene }\end{array}$} & 1383 & 231 & $n / a^{b}$ & 0.74 & 0.07 & 0.71 \\
\hline & 1387 & 221 & 0.82 & 0.89 & 0.09 & 0.63 \\
\hline & 1387 & 171 & 0.61 & 0.52 & 0.14 & $<0.03$ \\
\hline & 1387 & 242 & 0.68 & 0.67 & -0.21 & 0.31 \\
\hline & 1391 & 217 & 0.26 & 0.71 & 0.00 & 0.09 \\
\hline & 1395 & 209 & 0.37 & 0.32 & 0.14 & $<0.03$ \\
\hline & 1395 & 239 & 0.61 & 0.78 & 0.19 & 0.28 \\
\hline & 1397 & 189 & 0.82 & 0.72 & 0.15 & 0.37 \\
\hline
\end{tabular}




\begin{tabular}{|c|c|c|c|c|c|c|}
\hline $\begin{array}{l}\text { Known compound } \\
\text { letter and name }\end{array}$ & $\begin{array}{c}\text { Retentio } \\
n \text { index }\end{array}$ & $\begin{array}{c}\text { Integratio } \\
n \mathrm{~m} / \mathrm{z}\end{array}$ & $\begin{array}{c}\text { Isoprene } \\
\text { correlatio } \\
n\end{array}$ & $\begin{array}{c}\text { Pinene } \\
\text { correlatio } \\
n\end{array}$ & $\begin{array}{l}\text { Levoglucosa } \\
n \text { correlation }\end{array}$ & $\begin{array}{c}\text { Averag } \\
\text { e } F_{P} \\
\text { (IOP1) }\end{array}$ \\
\hline & 1401 & 171 & 0.86 & 0.82 & 0.03 & 0.04 \\
\hline & 1405 & 189 & 0.88 & 0.70 & 0.13 & 0.30 \\
\hline & 1417 & 179 & 0.52 & 0.54 & -0.02 & 0.05 \\
\hline & 1419 & 129 & 0.91 & 0.86 & -0.01 & 0.08 \\
\hline & 1421 & 191 & 0.91 & 0.75 & 0.04 & 0.79 \\
\hline & 1425 & 142 & 0.61 & 0.82 & 0.03 & $<0.03$ \\
\hline & 1436 & 127 & 0.57 & 0.66 & 0.19 & $<0.03$ \\
\hline & 1437 & 217 & 0.87 & 0.82 & 0.02 & 0.11 \\
\hline & 1437 & 268 & 0.57 & 0.76 & 0.39 & 0.40 \\
\hline & 1441 & 219 & 0.84 & 0.73 & 0.04 & 0.40 \\
\hline & 1461 & 244 & 0.75 & 0.65 & -0.07 & 0.41 \\
\hline & 1462 & 161 & 0.70 & 0.66 & -0.04 & 0.03 \\
\hline & 1476 & 211 & 0.62 & 0.71 & 0.17 & $<0.03$ \\
\hline & 1479 & 142 & 0.87 & 0.90 & -0.03 & 0.11 \\
\hline & 1481 & 228 & 0.78 & 0.76 & -0.03 & 0.24 \\
\hline & 1485 & 211 & 0.66 & 0.74 & 0.15 & $<0.03$ \\
\hline & 1508 & 196 & 0.52 & 0.60 & 0.08 & 0.04 \\
\hline E: 2-methythreitol & 1523 & 219 & $n / a^{b}$ & 0.72 & 0.14 & 0.38 \\
\hline \multirow[t]{2}{*}{ F: pinonic acid } & 1524 & 171 & 0.88 & $n / a^{b}$ & -0.11 & 0.03 \\
\hline & 1533 & 211 & 0.43 & 0.35 & 0.27 & 0.05 \\
\hline \multirow[t]{3}{*}{ G: 2-methyerythritol } & 1542 & 219 & $n / a^{b}$ & 0.71 & 0.13 & 0.63 \\
\hline & 1552 & 228 & 0.33 & 0.46 & -0.13 & 0.13 \\
\hline & 1561 & 228 & 0.74 & 0.65 & -0.12 & 0.07 \\
\hline \multirow[t]{8}{*}{ H: 3-hydroxy glutaric acid } & 1565 & 349 & 0.75 & $n / a^{b}$ & 0.10 & 0.69 \\
\hline & 1567 & 228 & 0.78 & 0.66 & -0.09 & 0.12 \\
\hline & 1573 & 204 & 0.36 & 0.53 & 0.00 & 0.41 \\
\hline & 1583 & 129 & 0.67 & 0.72 & 0.04 & 0.12 \\
\hline & 1583 & 219 & 0.80 & 0.89 & 0.17 & 0.75 \\
\hline & 1590 & 228 & 0.81 & 0.69 & -0.09 & 0.21 \\
\hline & 1594 & 342 & 0.59 & 0.63 & 0.17 & 0.46 \\
\hline & 1596 & 142 & 0.68 & 0.71 & 0.05 & 0.06 \\
\hline \multirow{6}{*}{$\begin{array}{l}\text { I: 3-acetyl pentanedioic } \\
\text { acid }^{\mathrm{a}}\end{array}$} & 1603 & 158 & 0.71 & $n / a^{b}$ & 0.11 & 0.54 \\
\hline & 1606 & 233 & 0.69 & 0.89 & 0.02 & 0.70 \\
\hline & 1617 & 271 & 0.79 & 0.81 & 0.08 & 0.55 \\
\hline & 1628 & 228 & 0.79 & 0.70 & -0.09 & 0.15 \\
\hline & 1636 & 233 & 0.73 & 0.80 & 0.06 & 0.62 \\
\hline & 1639 & 127 & 0.70 & 0.81 & -0.11 & $<0.03$ \\
\hline \multirow[t]{2}{*}{ J: pinic acid } & 1662 & 129 & 0.68 & $n / a^{b}$ & -0.11 & 0.25 \\
\hline & 1673 & 247 & 0.72 & 0.86 & 0.02 & 0.72 \\
\hline
\end{tabular}




\begin{tabular}{|c|c|c|c|c|c|c|}
\hline $\begin{array}{l}\text { Known compound } \\
\text { letter and name }\end{array}$ & $\begin{array}{c}\text { Retentio } \\
n \text { index }\end{array}$ & $\begin{array}{c}\text { Integratio } \\
n \mathrm{~m} / \mathrm{z}\end{array}$ & $\begin{array}{c}\text { Isoprene } \\
\text { correlatio } \\
n\end{array}$ & $\begin{array}{c}\text { Pinene } \\
\text { correlatio } \\
n\end{array}$ & $\begin{array}{l}\text { Levoglucosa } \\
n \text { correlation }\end{array}$ & $\begin{array}{l}\text { Averag } \\
\text { e } F_{P} \\
\text { (IOP1) }\end{array}$ \\
\hline & 1681 & 129 & 0.42 & 0.47 & 0.13 & 0.07 \\
\hline \multirow[t]{4}{*}{ K: levogluclosan } & 1697 & 204 & 0.14 & 0.11 & $n / a^{b}$ & 0.96 \\
\hline & 1700 & 228 & 0.72 & 0.82 & -0.03 & $<0.03$ \\
\hline & 1705 & 228 & 0.72 & 0.81 & -0.04 & 0.04 \\
\hline & 1710 & 217 & 0.43 & 0.26 & 0.65 & 0.53 \\
\hline \multirow[t]{4}{*}{ L: tricarballylic acid } & 1723 & 377 & 0.74 & $n / a^{b}$ & 0.00 & 0.61 \\
\hline & 1725 & 211 & 0.68 & 0.68 & 0.05 & 0.37 \\
\hline & 1733 & 217 & 0.15 & 0.15 & 0.70 & 0.97 \\
\hline & 1742 & 228 & 0.49 & 0.61 & -0.02 & 0.07 \\
\hline \multirow{22}{*}{$\begin{array}{l}\text { M: 3-methyl-1,2,3-butane } \\
\text { tricarboxylic acid } \\
\text { (MBTCA) }\end{array}$} & 1744 & 204 & 0.80 & $n / a^{b}$ & 0.09 & 0.56 \\
\hline & 1775 & 197 & 0.62 & 0.62 & 0.18 & 0.06 \\
\hline & 1790 & 317 & 0.48 & 0.55 & 0.07 & 0.23 \\
\hline & 1795 & 228 & 0.36 & 0.44 & -0.04 & $<0.03$ \\
\hline & 1816 & 405 & 0.85 & 0.78 & 0.10 & 0.66 \\
\hline & 1831 & 129 & 0.54 & 0.54 & 0.05 & 0.03 \\
\hline & 1837 & 228 & 0.49 & 0.66 & -0.02 & 0.05 \\
\hline & 1875 & 228 & 0.60 & 0.76 & 0.06 & 0.22 \\
\hline & 1882 & 204 & 0.07 & 0.00 & 0.09 & 0.82 \\
\hline & 1895 & 262 & 0.47 & 0.61 & -0.05 & 0.40 \\
\hline & 1899 & 204 & 0.12 & 0.15 & 0.65 & 1.00 \\
\hline & 1901 & 417 & 0.86 & 0.76 & 0.08 & 0.62 \\
\hline & 1925 & 204 & 0.07 & 0.14 & 0.54 & 0.84 \\
\hline & 1929 & 417 & 0.84 & 0.73 & 0.10 & 0.67 \\
\hline & 1931 & 228 & 0.53 & 0.68 & -0.01 & 0.04 \\
\hline & 1953 & 299 & 0.34 & 0.52 & 0.06 & $<0.03$ \\
\hline & 1959 & 262 & 0.44 & 0.56 & -0.06 & 0.37 \\
\hline & 1962 & 204 & -0.01 & -0.09 & 0.04 & 1.00 \\
\hline & 1969 & 228 & 0.60 & 0.80 & 0.02 & 0.14 \\
\hline & 1985 & 204 & 0.10 & 0.09 & 0.59 & 1.00 \\
\hline & 2026 & 228 & 0.54 & 0.72 & -0.03 & 0.04 \\
\hline & 2120 & 228 & 0.61 & 0.73 & -0.03 & 0.06 \\
\hline
\end{tabular}

based on mass spectrum identified as 3-acetyl pentanedioic acid by Jaoui et al.

${ }^{\mathrm{b}}$ Compounds for which correlation is marked as $\mathrm{n} / \mathrm{a}$ are used as the known compounds for correlation with unknown compounds 